\title{
Routes of Agulhas rings in the southeastern Cape Basin
}

\author{
Guillaume Dencausse, Michel Arhan*, Sabrina Speich \\ Laboratoire de Physique des Océans, CNRS/IFREMER/IRD/UBO, Centre de Brest, B.P.70, 29280 Plouzané, France
}

\section{A R T I C L E I N F O}

\section{Article history:}

Received 30 October 2009

Received in revised form

2 July 2010

Accepted 6 July 2010

Available online 2 August 2010

\section{Keywords:}

Agulhas rings

Indo-Atlantic exchanges

Altimetry

\begin{abstract}
A B S T R A C T
Using weekly sea surface height data, Agulhas rings from the period October 1992 to December 2006 are detected and tracked, from their formation dates and throughout the Cape Basin. While 102 of them formed at the Agulhas Current retroflection, their subsequent subdivisions and junctions led to 199 trajectories. The rings geographical probability of presence shows two maxima. One, related to numerous ring passages, lies in the submarine bight formed by the Erica seamount, the Schmitt-Ott seamount, and the northeastern tip of the Agulhas Ridge. The other one, to be ascribed to topographic blocking of the eddies, is southeast of the latter obstacle. On the basis of topographic effects three routes for Agulhas rings are distinguished, a Northern route for rings that enter the south-Atlantic northeast of the Erica seamount, a Central one for those passing westward between this seamount and the tip of the Agulhas Ridge, and a Southern one farther south. Despite its bathymetric obstacles, the central route is the dominant one, both in terms of percentage of eddy crossings at its definition segment, and in terms of conveyed volume transport. Specific behaviours of rings along each route are described, referring to observations in previous studies. Some rings from the Northern route interact with the flow regime of the South African continental slope. The southernmost trajectories of the Central route are thought to settle the location of the climatological Subtropical Front in that region. The rings of the Southern route experience important core property alteration as they transit through the subantarctic domain.
\end{abstract}

(c) 2010 Elsevier Ltd. All rights reserved.

\section{Introduction}

Several studies using satellite altimetric data have led to a general agreement on the way the anticyclonic rings issued from the retroflection of the Agulhas Current cross the South Atlantic ocean (Gordon and Haxby, 1990; Byrne et al., 1995; Schouten et al., 2000). Once they have escaped the southeastern Cape Basin, these eddies propagate westward as isolated structures at latitudes $20^{\circ} \mathrm{S}-35^{\circ} \mathrm{S}$, generally slowing down at the approach of bathymetric ridges. They have life-times up to 3-4 years.

The behaviour of Agulhas rings in the southeastern Cape Basin closer to their formation region is more complex, and was sometimes presented in contrasted manners. Garzoli and Gordon (1996), Garzoli et al. (1997) and Goni et al. (1997), emphasizing the net northwestward translation of the rings in the Cape Basin, defined a relatively narrow ring corridor in which the rings would propagate and where Atlantic water from the west and Indian Ocean water from the east would mix. Boebel et al. (2003), on the other hand, underlined the turbulent character of the southeastern Cape Basin and the ensuing intense water mass mixing. Analysing subsurface float trajectories and altimeter-deduced sea surface height $(\mathrm{SSH})$ data, they described the vigorous

\footnotetext{
* Corresponding author. Tel.: +33 298224285; fax: +33 298224496.

E-mail address: michel.arhan@ifremer.fr (M. Arhan).
}

interactions that occur between the anticyclonic rings and numerous cyclones originating at the African continental slope, on the shoreward side of the Agulhas Current, or in the Subantarctic Zone. They named this region the Cape Cauldron. In keeping with this view, Schouten et al. (2000) using four years of satellite altimetry data, and Schmid et al. (2003) analysing one individual ring, revealed the significant decay of Agulhas rings in the Cape Basin.

Other issues regarding the properties and behaviour of Agulhas rings have been addressed, including their inner velocity structures (Clement and Gordon, 1995), the diversity of their hydrographic properties (Garzoli et al., 1999; McDonagh et al., 1999; Arhan et al., 1999), and their interactions with the oceanic regime along the western coast of South Africa (Shillington et al., 1990; Lutjeharms et al., 1991; Duncombe Rae et al., 1992; Rubio et al., 2009). The velocity signatures of juvenile rings may reach down to more than $3000 \mathrm{~m}$. The depth to which they can trap water can be more than $1600 \mathrm{~m}$ for young rings according to Schmid et al. (2003), yet it is difficult to determine, penalizing the estimation of their water transport (Boebel et al., 2003). Richardson (2007), using subsurface floats and surface drifters, estimated an Agulhas leakage (from the Indian to Atlantic Ocean) of about $15 \mathrm{~Sv}$ in the upper $1000 \mathrm{~m}\left(1 \mathrm{~Sv}=10^{6} \mathrm{~m}^{3} \mathrm{~s}\right)$, of which 10-13 Sv should be ascribed to Agulhas rings. The water properties conveyed by rings into the Atlantic Ocean are dependent on the duration and period of year that these structures spend in 


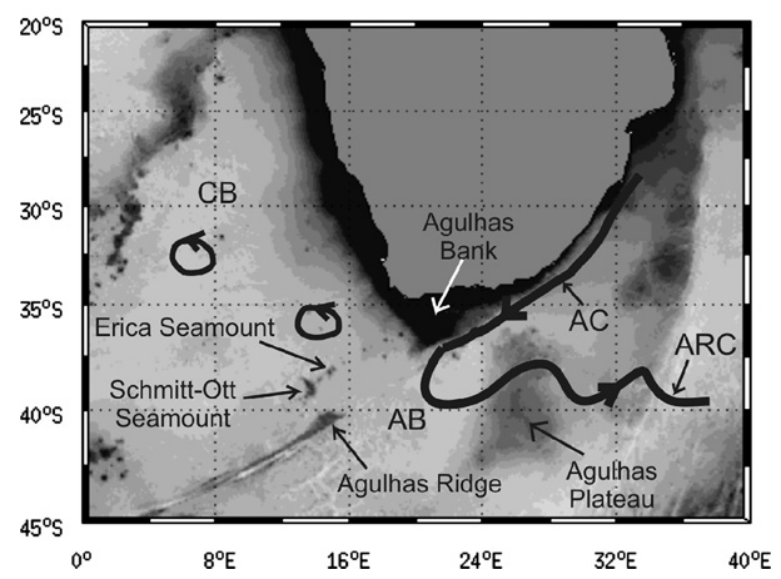

Fig. 1. Bathymetric map of the area of study, with the locations of the Cape Basin $(\mathrm{CB})$ and Agulhas Basin (AB), and topographic features cited in the text. The solid lines show the schematic track of the Agulhas Current (AC), Agulhas Return Current (ARC), and a few Agulhas rings.

their formation region. Agulhas rings propagating in the vicinity of the continental shelf were shown to contribute to water exchange between the ocean interior and the Benguela upwelling regime.

Although a few observations (Arhan et al., 1999; Schouten et al., 2000) and model studies (Kamenkovich et al., 1996; Biastoch and Krauss, 1999; Herbette et al., 2003, 2005) suggest that the Agulhas Ridge and neighbouring seamounts located immediately west of the rings formation region (Fig. 1) should influence their behaviour, this issue was probably not sufficiently examined considering its consequences on the rings tracks, their ensuing air-sea exchanges, and more generally on their decay. An accurate estimation of the rings decay itself requires a precise determination of their formation dates. This could not be done in some previous studies, when the sole availability of $\mathrm{SSH}$ anomalies (instead of absolute $\mathrm{SSH}$ ) made it difficult to detect the exact times of eddy separation from the Agulhas retroflection.

Taking advantage of the present availability of long time series of absolute $\mathrm{SSH}$, we here present a statistical analysis of Agulhas rings behaviour in the Cape Basin that should contribute filling the above gaps of knowledge. The analysis rests on a weekly exhaustive detection of locations, SSH signatures, and diameters of Agulhas rings present in the Cape Basin between October 1992 and December 2006, including their dates of formation, and possible splitting and merging events. Particular focus is put on the role played by the Agulhas Ridge and the Schmitt-Ott and Erica seamounts (Fig. 1) in initiating several types of trajectories along which rings behave differently. This study extends a companion analysis of the Agulhas retroflection based on the same absolute SSH data (Dencausse et al., 2010). The connection is made between the eddy shedding events as detected from the analysis of the Agulhas Current retroflection in the previous article, and those obtained through Agulhas ring detection.

\section{Data and methods}

\subsection{Data}

The absolute SSH fields used for this study are distributed by the archiving, validation and interpretation of satellite oceanographic database (AVISO). They are produced by Ssalto/Duacs with support of the French Centre National d'Etudes Spatiales (http://www.aviso.oceanobs.com/duacs/). They combine a multisatellite SSH anomaly (TOPEX/POSEIDON, JASON-1, ERS: Le Traon et al., 1998; Ducet et al., 2000), and a mean dynamic topography itself combining in situ data, altimetry, and the EIGEN-GRACE05S geoïd (Rio and Hernandez, 2004). For brevity in the following we mean the absolute SSH when writing "SSH", and specify "anomaly" when needed. These data are identical to those used in an article on the Agulhas Current retroflection by the same authors (Dencausse et al., 2010), except for two points. As the study of the Agulhas rings was subsequent to the one on the retroflection, it benefited from a longer time series, from 14 October 1992 to 3 January 2007, that is, 743 weeks (14.3 year). By that time a new version of the mean dynamic topography (Rio05; Rio et al., 2005) was also inserted in the altimetric products. This is of minor importance here, as the eddy tracking procedure uses the SSH anomalies (see below), the SSH itself being only used to determine the dates and locations of separation from the current retroflection.

\subsection{Wavelet analysis}

The procedure used to track the anticyclones rests on a wavelet analysis, a technique of signal decomposition in orthogonal wave packets which, owing to its providing both spatial and frequency information has been largely used to detect coherent structures in spatial fields. Following Doglioli et al. (2007) who applied it to vorticity fields in order to follow eddies south of Africa in a high resolution model, we here use a 2-dimension version of the same tool to detect and follow anticyclonic vortices in altimetric fields. The number of spectral components associated with the eddies was adjusted after a few trials in order to only retain Agulhas rings and filter out patterns of smaller size such as filaments. To each Agulhas ring is associated a group of grid points and a centre located at an extremum of the analysed parameter. Ring surfaces and equivalent ring diameters may therefore be computed.

The spatial contours ascribed to eddies by the wavelet analysis are of course only an indication of the structure coherency as determined by the mathematical tool. Working on the $\mathrm{SSH}$ anomalies, the method produced ring circumferences that were close to the largest positive contour of SSH anomaly compatible with the requirement of compactness imposed by the filtering. The inferred radius is admittedly not related to any dynamical criterion. It is generally larger than the radius of maximum swirl velocity, but smaller than the outer reach of the anticyclonic flow.

When estimating volume transport by an eddy, one is led to consider the distance from the eddy centre within which water is trapped and entrained by the structure. Flierl (1981) demonstrated that those particles whose swirl velocities exceed the eddy translation speed are entrained, which implies a time-variable trapping distance. Applying this criterion to the case of an Agulhas ring observed near $23^{\circ} \mathrm{S}-7^{\circ} \mathrm{W}$ some $2500 \mathrm{~km}$ from its formation region, McCartney and Woodgate-Jones (1991) found an equivalent near surface trapping radius close to the radius of maximum azimuthal velocity when assuming a drift speed of $0.1 \mathrm{~m} / \mathrm{s}$ for the eddy, and about 1.7 times the latter for a drift speed of $0.05 \mathrm{~m} / \mathrm{s}$. Donners et al. (2004), working on simulated rings in the southern Cape Basin, found surface trapping radii of about twice the radius of maximum velocity over one year. The decrease of the azimuthal velocities with depth naturally induces a similar trend on the trapping radius. The results just cited suggest that the equivalent radius inferred from the wavelet analysis, generally comprised between the radius of maximum azimuthal velocity and the outermost closed SSH contours, might be used for a rough estimation of water transport by the rings, which we present in Section 5 . Such computation is certainly subject to large uncertainties. There are indications that the wavelet-deduced area might, at 
places where the rings drift speeds are very small, encompass water from outside the ring that is being pulled around the trapped core. On the other hand, the large scale decrease of the wavelet-deduced ring areas across the Cape Basin, likely representative of the lateral erosion of the real rings, is a necessary ingredient in the estimation of the transport decrease itself.

\subsection{Tracking methodology}

Once a structure had been detected at a given date, it was tracked by performing the wavelet analysis on the parameter field of the following week, and by checking whether the centre of a structure detected at this new date would fall within the previous eddy contour. If so, the structure was assumed to be the same, and the process repeated until no anticyclone was found within the preceding contour. The tracking procedure was systematically resumed the week following an interruption, and we were

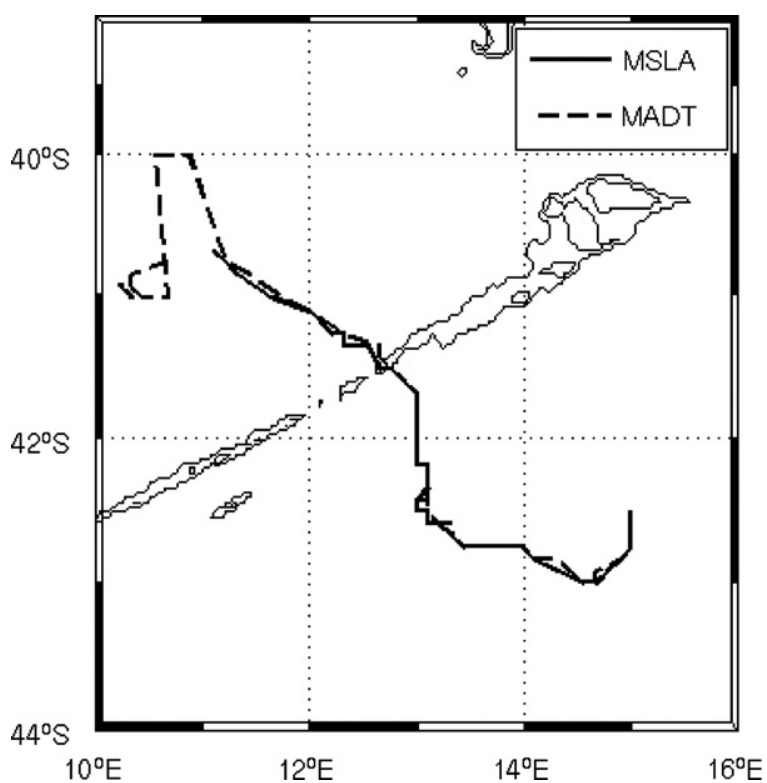

Fig. 2. Trajectories of an Agulhas ring obtained from $1 / 9^{\circ}$-interpolated SSH fields (dashed) and SSH anomaly fields (continuous). Bathymetric contours (thin continuous) are 2000 and $2500 \mathrm{~m}$. sometimes led to consider some of these as artificial (e.g., resulting from a too rapid ring displacement), and to join end to end pieces of trajectories. We tracked the Agulhas rings in the geographical domain $26^{\circ} \mathrm{S}-50^{\circ} \mathrm{S} / 0^{\circ} \mathrm{E}-28.5^{\circ} \mathrm{E}$, a wide area containing most of the real ring trajectories, except for 11 of them which extend farther (north) westward.

While in some other studies eddies were tracked from their surface vorticity signatures, a few satisfactory tests led us to use the original fields of sea level. We had, however, to choose between using the SSH itself, or SSH anomalies. Comparisons (Fig. 2) showed that both parameters led to similar results away from the Agulhas Current retroflection where the mean dynamic topography shows spatial variations comparable to those of the anomalies. The SSHdeduced trajectories, however, were often found longer than those inferred from the anomalies, an artefact caused by the presence of weak structures in the mean field. For this reason we chose to use the SSH anomalies, except at the very beginning of the trajectories where SSH was required to identify the associated separation events of the Agulhas Current retroflection.

\subsection{Application to Agulhas rings}

Some refinement of the spatial resolution of the $\mathrm{SSH}$ anomaly fields proved necessary before they could be used for the tracking of Agulhas rings (Fig. 3 ). The coarse $1 / 3^{\circ}$ grid interval indeed led to irregular eddy shapes, themselves resulting in artificial tracking interruptions or tracking jumps between neighbouring structures. In order to avoid such problems the data were interpolated to $1 / 9^{\circ}$ intervals.

Dencausse et al. (2010) studied the longitudinal pulsations of the Agulhas Current retroflection by defining a "retroflection point" at the westernmost location of the Indian Ocean water protrusion. We conventionally chose to start the Agulhas ring trajectories the week preceding the eastward jump of the retroflection point caused by the ring shedding events. The trajectories naturally end on the weeks preceding the loss of the rings by the wavelet analysis, at those locations where the abovementioned attempts to resume the tracking procedure failed.

Visual examination of the weekly SSH fields revealed that the SSH ring signatures often existed for a few weeks (3-4 at most) after the end of the tracking, but were too weak to be detected by the wavelet analysis. The eddy life durations are therefore somewhat underestimated. To this we should add that, in case of eddy subduction beneath lighter water, the loss of a ring
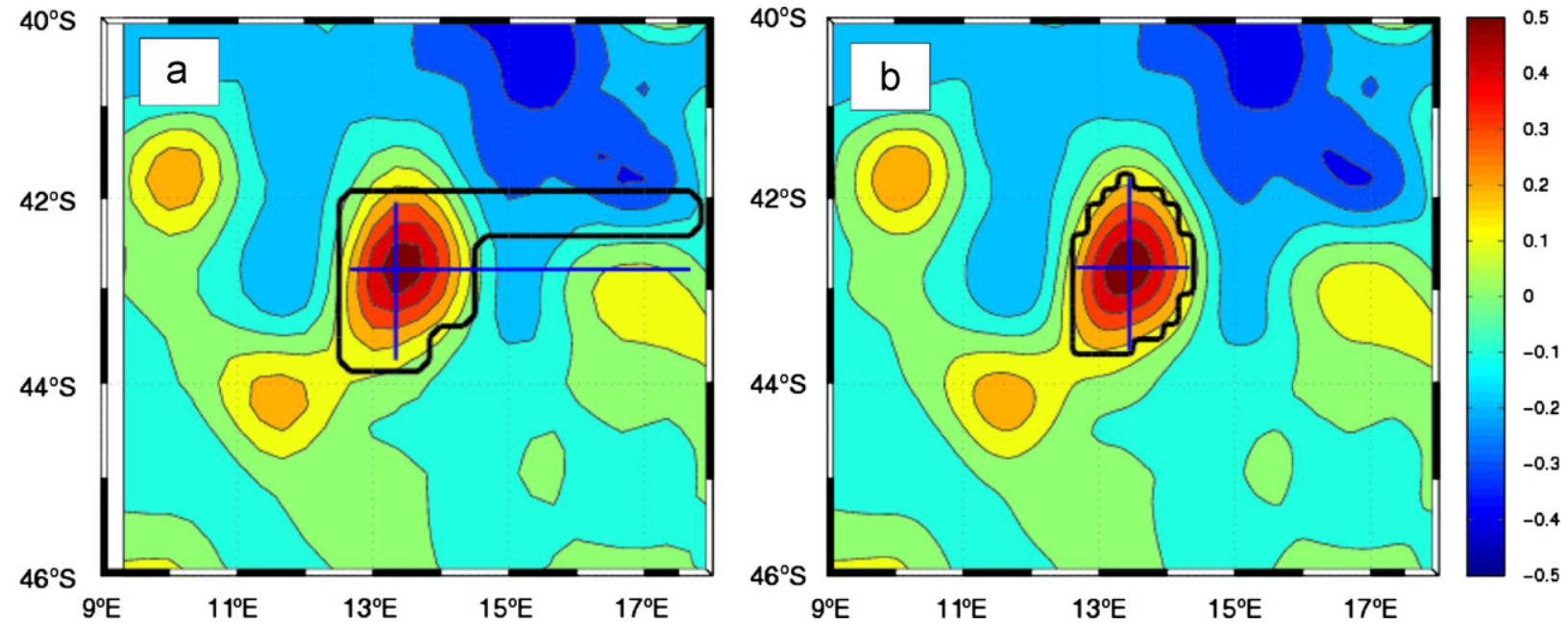

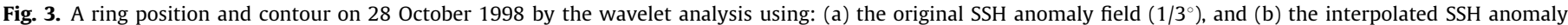
field $\left(1 / 9^{\circ}\right)$. 
altimetric signature does not necessarily imply its total dissipation (Herbette et al., 2004). These uncertainties on the times and locations of eddy disappearances, however, little affect our analysis mostly focused on the relation between the ring trajectories and the seamounts at $14^{\circ} \mathrm{E}-15^{\circ} \mathrm{E}$.

In case of ring subdivisions, the trajectory of the larger resulting sub-eddy was considered the continuation of the initial one, while the smaller sub-structure was regarded as a new ring with a trajectory conventionally starting the week preceding the subdivision. Similarly, in case of ring merging, the resulting eddy was considered the continuation of the larger initial structure.

\section{The whole set of Agulhas ring trajectories}

We name the Agulhas rings directly stemming from the Agulhas Current retroflection "initial rings". We specified above that, in case of ring subdivision, the larger resulting structure was considered the continuation of the initial eddy. The other, smaller, structures resulting from the subdivision are named "sub-rings", to remind of their different formation process. Their age is counted starting from the week preceding the subdivision. For

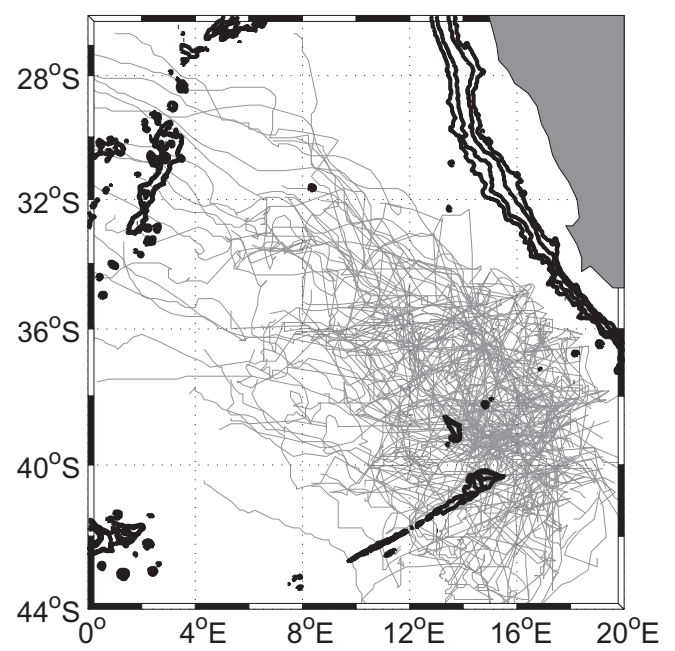

Fig. 4. Grey lines show the 199 ring trajectories detected between 14 October 1992 and 3 January 2007. Bathymetric contours are 500, 1000, 2000 and $2500 \mathrm{~m}$. these structures, however, we define a "corrected age" as the addition of their age to the age of the initial ring at the time of the subdivision.

\subsection{Counting of Agulhas rings}

A total of 199 trajectories of rings and sub-rings were identified during the period 14 October 1992-3 January 2007 (Fig. 4). In these are not counted the Agulhas rings present in the studied area on 14 October 1992, as we had no means to determine whether they were initial or sub-rings. On the other hand, 6 identified rings were still present in the study area on 3 January 2007. The distinction between a regime of relatively regular northwestward-oriented trajectories in the northwestern half of the Cape Basin, and the Cape Cauldron turbulent regime in the southeastern half of the basin stands out in Fig. 4. The area covered by the trajectories, however, extends farther southwestward than both the Agulhas eddy corridor proposed by Garzoli et al. (1997), the entry of which was northeast of $\sim 37.5^{\circ} \mathrm{S}-12.5^{\circ} \mathrm{E}$, and Boebel's et al. (2003) Cape Cauldron whose southern corner was at $\sim 41^{\circ} \mathrm{S}-13^{\circ} \mathrm{E}$. Some anticyclones shed from the Agulhas Current retroflection and eventually entering the South Atlantic were observed south of the latter point.

Table 1 presents basic statistical characteristics deduced from these trajectories. The accumulated tracking duration of all 199 trajectories is 4342 weeks ( 83.2 years), and the average corrected life duration of an Agulhas ring is $26.1 \pm 19$ weeks ( $\sim 6$ months). From the total tracking time we deduce that 6.6 rings are simultaneously present, on average, in the study area. This number is on the high side of the 2-to-7 range proposed by Goni et al. (1997), a possible consequence of improved spatiotemporal resolutions of multi-satellite altimetric products.

Out of the 199 listed Agulhas rings, 102 were initial rings, and 97 were sub-rings. Only considering the initial rings, Fig. 5 showing the dates and longitudes of their first detection reveals a frequent concomitance between the first detection of initial rings and the events of water separation from the Agulhas Current retroflection as defined in Dencausse et al. (2010). In the same figure, characterizing the locations of the rings from their centres, and those of the shedding events from the westernmost positions of the Agulhas Current explains the longitude differences between the two displayed types of events. In Dencausse et al. (2010) the Agulhas Current retroflection was only studied until May 2005. In order to compare the results from the two studies, the

Table 1

Characteristics of the 199 ring trajectories identified between 14 October 1992 and 3 January 2007.

\begin{tabular}{|c|c|c|c|c|}
\hline & & & Total & Per year \\
\hline \multirow{3}{*}{$\begin{array}{l}\text { Correspondence between numbers of } \\
\text { shedding events, initial rings and sub- } \\
\text { rings }\end{array}$} & \multicolumn{2}{|l|}{ Shedding events } & $\begin{array}{l}86 \text { (including } 3 \\
\text { "temporary") }\end{array}$ & 6.1 \\
\hline & \multicolumn{2}{|l|}{ Initial rings } & 102 & 7.2 \\
\hline & \multicolumn{2}{|l|}{ Sub-rings } & 97 & 6.8 \\
\hline \multirow[t]{3}{*}{ Characteristics of all 199 trajectories } & \multicolumn{2}{|l|}{ Total trajectories identified } & $199(102+97)$ & 14.0 \\
\hline & \multicolumn{2}{|l|}{ Total tracking time (weeks) } & 4342 & \\
\hline & \multicolumn{2}{|c|}{ Life-time, with "corrected age" (weeks) } & $26.1(\mathrm{std}=19.4)$ & \\
\hline \multirow[t]{6}{*}{ Characteristics of 102 initial rings (IR) } & \multirow[t]{3}{*}{ IR that never subdivide } & Number/\% of initial rings & $47 / 46.1 \%$ & 3.3 \\
\hline & & $\begin{array}{l}\% \text { of tracking time of all } 199 \\
\text { trajectories }\end{array}$ & $18.9 \%$ & \\
\hline & & Life-time (weeks) & $17.5(\mathrm{std}=15.9)$ & \\
\hline & \multirow{3}{*}{$\begin{array}{l}\text { IR that subdivide (statistics } \\
\text { before subdivision) }\end{array}$} & Number/\% of initial eddies & $55 / 53.9 \%$ & 3.9 \\
\hline & & $\begin{array}{l}\% \text { of tracking time of all } 199 \\
\text { trajectories }\end{array}$ & $9.8 \%$ & \\
\hline & & Life-time (weeks) & $7.7(\mathrm{std}=7.0)$ & \\
\hline
\end{tabular}

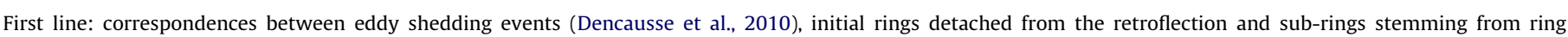

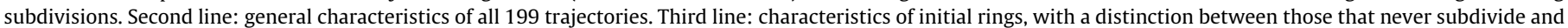
those that do. "Std" stands for standard deviation. 

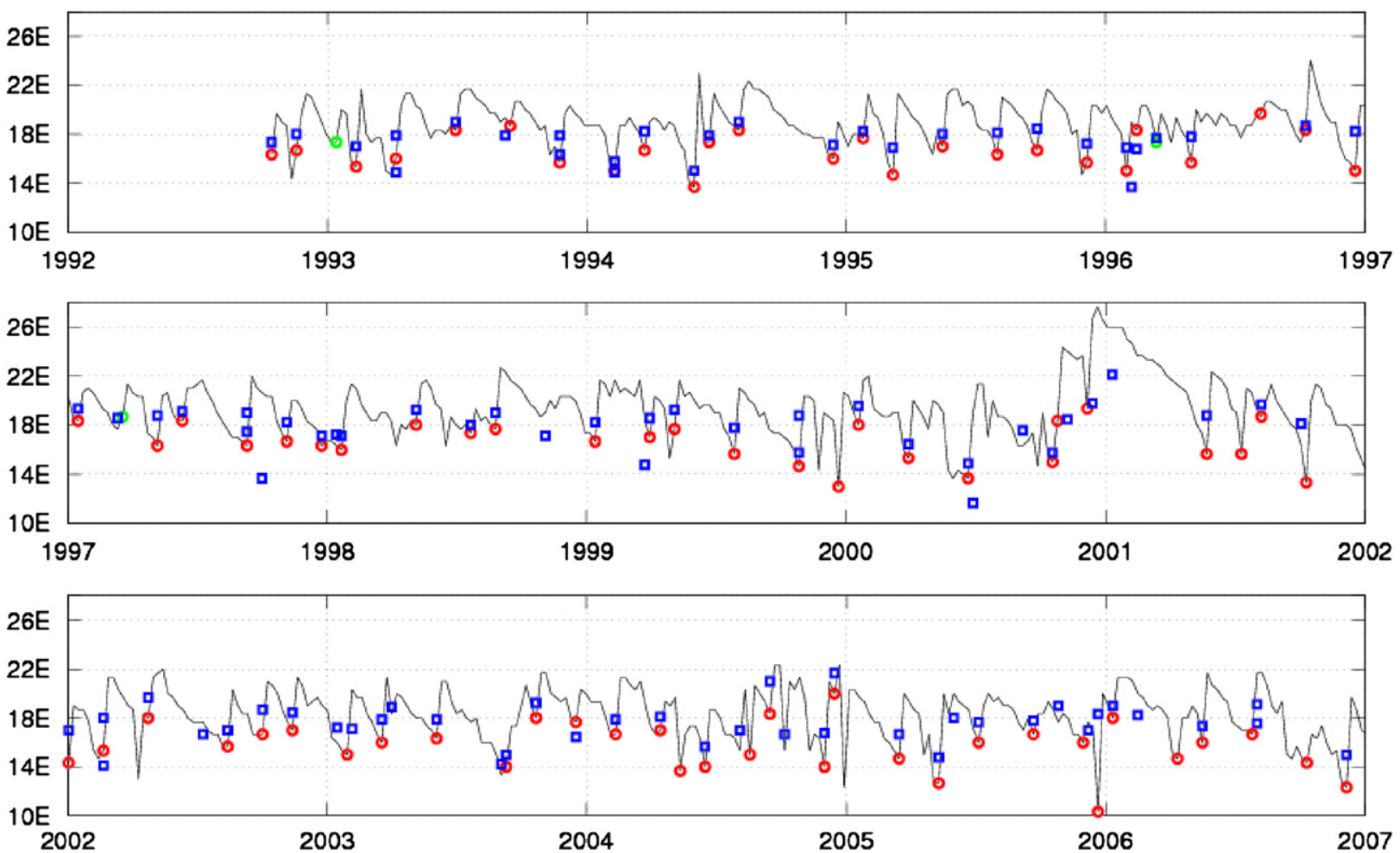

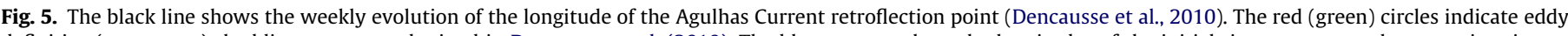

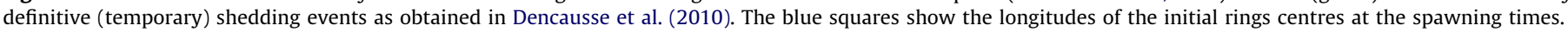

Table 2

Correspondences between eddy shedding events as identified by Dencausse et al. (2010) and the spawning of initial rings at the retroflection.

\begin{tabular}{lllll}
\hline $\begin{array}{l}\text { Correspondence between } \\
\text { shedding events (SE) and } \\
\text { initial ring spawning (IRS) }\end{array}$ & SE/1 IRS & 1 SE/2 IRS & 1 SE/0 IRS & 0 SE/1 IRS \\
\hline $\begin{array}{lllll}\text { Number } \\
\text { \% of the } 86 \mathrm{SE}\end{array}$ & 63 & 16 & 7 & 7 \\
\hline
\end{tabular}

Shedding events may correspond to the spawning of a single ring, of two rings simultaneously, or of no ring. Initial rings can also detach from the retroflection without a corresponding eddy shedding event.

identification of separation events as described in that article was extended to 3 January 2007. Facing the 102 initial rings of this study we only counted 86 water separation events, including 3 temporary ones. Table 2 further details the relation between water separation events from the retroflection and initial ring formations. We observed 63 one-to-one connections between the two types of events, which means that $73 \%$ of water separation events lead to the formation of a single Agulhas ring. To 16 separations were associated quasi-simultaneous sheddings of two initial rings, while 7 other separations did not lead to any eddy formation. The latter apparent contradiction concerns separation events occurring over several weeks and feeding an already detached (and tracked) ring. Finally, Table 2 refers to 7 rings formed without any water separation from the Agulhas retroflection, in the sense defined in Dencausse et al. (2010). This other apparent inconsistency refers to separated water parcels that were subsequently re-captured by the Agulhas retroflection for less than a week, in which case it was decided not to count the subsequent new separation, although an initial ring was formed.
The above differences between the number of water separation events from the retroflection (86), the number of initial eddies (102), and the total number of trajectories (199) point to the difficulty to define and count the anticyclonic vortices shed by the retroflection and entering the Atlantic Ocean. As an illustration of this difficulty, the nearly one-to-one ratio found here between the number of splitting events and that of initial eddies significantly exceeds the 0.65 ratio found by Schouten et al. (2000) using SSH anomalies and a different detection method over a 4-year long observational period. This discrepancy certainly partly results from differences in the shedding events detected in each study (Dencausse et al., 2010), but also from differences in the way of defining and counting initial rings, as detailed above.

\section{2. "Initial rings" and "sub-rings"}

The positions of the 102 initial rings when first detected, shown in Fig. 6, are concentrated east of $16^{\circ}$ E. Initial positions more to the west correspond to unusual westward penetrations of the Agulhas Current retroflection.

Of those 102 initial rings, nearly half (47) never subdivide. Their trajectories are represented in Fig. 7. Their average life-time is $17.4 \pm 15.9$ weeks, that is, about 10 weeks less than the average corrected life-time for all rings, an indication that subdivision is not the main factor in decreasing ring durability. Although there is no straightforward explanation to this, we note that initial rings with smaller diameters are likely those decaying faster or ending their lives at merging events (with larger structures), whereas larger rings whose sizes exceed the internal Rossby deformation radius are more prone to unstability and subdivision. Initial rings which do not subdivide are tracked for a cumulated duration of 820 weeks, which represents $18.9 \%$ of the tracking time of all 199 trajectories. Thus on average $18.9 \%$ of rings observed at any time in the studied area are initial rings that never subdivide. 


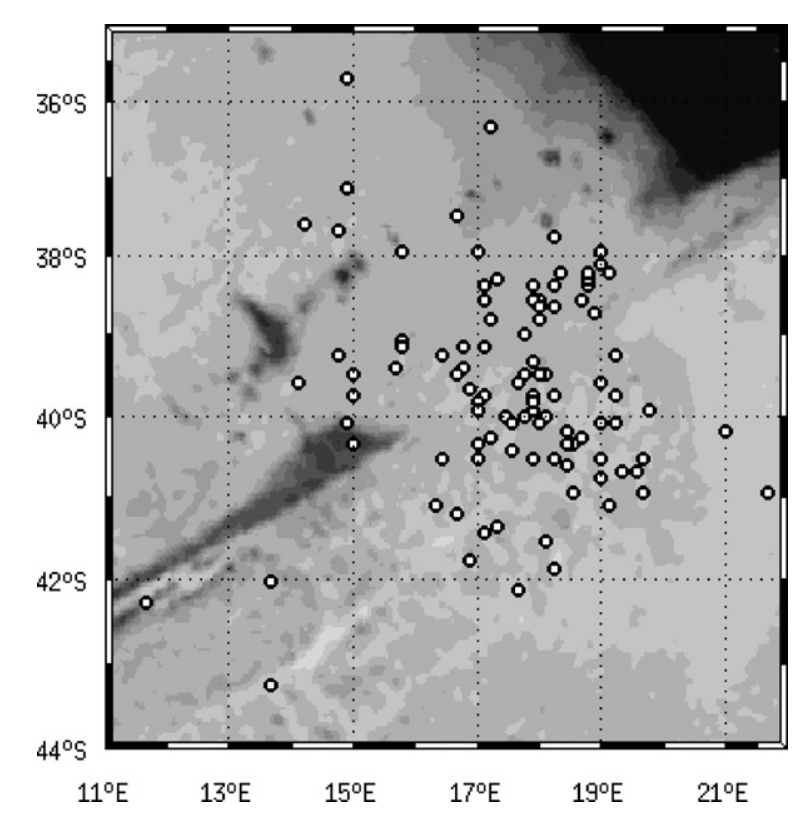

Fig. 6. Dots show the initial positions of rings directly shed from the Agulhas retroflection, referred to as "initial rings".

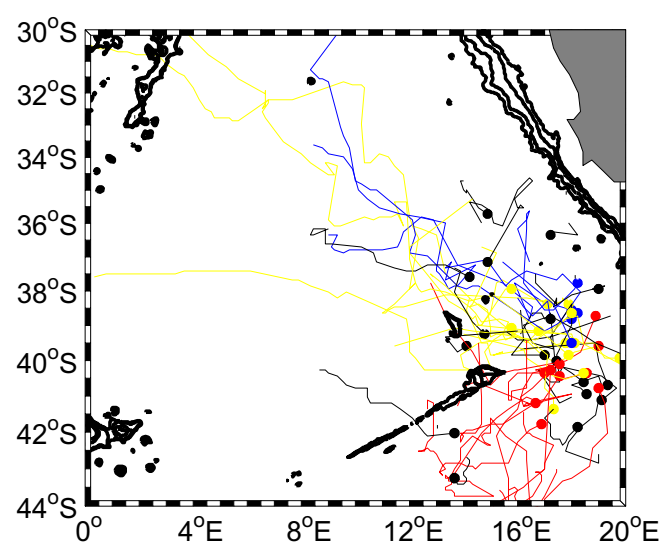

Fig. 7. Initial positions (dots) and trajectories of initial rings that never subdivide. Colours indicate the routes taken by the rings: blue for the Northern route, yellow for the Central route and red for the Southern route. In black are rings that do not belong to any route. Bathymetric contours are 500, 1000, 2000 and $2500 \mathrm{~m}$.

The 55 other initial rings may subdivide more than once. We counted 97 subdivisions, including subdivisions of sub-rings, whose positions are shown Fig. 8a. Based on the accumulated tracking time of all portions of trajectories after a subdivision, we find that $71.4 \%$ of rings observed at any time have undergone a subdivision. A majority of rings split east of, and near, the bathymetry west of the Agulhas Basin, pointing to a role of these obstacles in subdivision mechanisms. In order to better characterize this topographic effect, we show in Fig. $8 \mathrm{~b}$ the tracks of the subdivided vortices during 5 weeks after the splitting events. Only those subdivisions located in the domain $38^{\circ} \mathrm{S}-40^{\circ} \mathrm{S}$, $13^{\circ} \mathrm{E}-18^{\circ} \mathrm{E}$ around the obstacles are considered. Their number is 34 , out of which 28 (82\%) lead to diverging tracks of the subdivision products, one ring drifting northward and the other southward, before all of them eventually resume their westward drift. Only 5 (1) subdivisions produced rings propagating in a single northward (southward) direction. This analysis confirms the frequent occurrences of a behaviour previously observed for individual structures (e.g., Arhan et al., 1999).
We noted above that eddy trajectories end either when the associated SSH anomaly becomes too weak, or when the eddy merges with a larger structure. The latter situation was observed for 38 ring tracks, out of 199 . The positions of these junctions are represented in Fig. 9a. Their distribution resembles that of the subdivision locations, with a high concentration near the bathymetry west of the Agulhas Basin, a likely consequence of intense interactions with other rings and the bathymetry. The submarine bight formed by the Schmitt-Ott and Erica seamounts and the northeastern edge of the Agulhas Ridge appears a particularly favourable place for Agulhas ring merging. The final positions of all rings, including the 38 ones that have just been discussed, are shown in Fig. 9b. Many trajectories end near the retroflection, as some rings are reabsorbed by the retroflection, merge with larger rings, or simply dissipate. Farther west, ring penetration into the Cape Basin is regularly distributed to about $6^{\circ}$ E. West of this longitude, the rings seem to pursue their progression up to and past the Walvis Ridge.

\subsection{Space and time evolutions of ring characteristics}

Fig. 10 exhibits the spatial distributions of the probability of presence of the Agulhas rings (Fig.10a), and of their diameter, SSH anomalies and ages (Fig.10b-d), over the 14.3 years of the SSH time series. Two regions with a high probability of presence stand out in Fig. 10a, one in the afore-mentioned submarine bight, and the other one southeast of the Agulhas Ridge, between $12^{\circ} \mathrm{E}$ and $15^{\circ} \mathrm{E}$. The high probability in the former area certainly reflects the presence of numerous trajectories (Fig. 4), and possibly a tendency of Agulhas rings to slow down there because of interaction with the bathymetry. The situation seems different in the latter case, as Fig. 4 shows relatively few trajectories there. The high probability of presence south of the Agulhas Ridge is likely caused by the slowing down and stalling of rings close to the bathymetry, explaining the high corrected ages of rings in this region in regard to its proximity to the rings formation region. The corrected age spatial evolution reflects the general northwestward drift of Agulhas rings, which is accompanied by decreases in SSH anomalies and diameter values. The SSH anomaly at the centre of rings decreases faster than their diameter, the latter even keeping values similar to those in the retroflection region as far north as $31^{\circ} \mathrm{S}$ along the African shelf. Such different rates of decrease of diameter and SSH likely reflect different causes. The various events of a ring life, like splitting, merging, loss of its deep part on crossing the seamounts area, or cooling through air-sea exchange, all are associated with geostrophic adjustments that may affect theirs diameters and SSH anomalies differently. But another cause likely refers to the significance of the diameter parameter issued from the wavelet analysis. In Section $2 \mathrm{~b}$ we noted that the diameter values here used, though representative of the scale of the anticyclonic motion associated with the ring may, in cases when the ring translational velocity is low, include water particles from outside the structure (McCartney and Woodgate-Jones, 1991). We determined the spatial distribution of the Agulhas rings velocity modulus but do not present it in Fig. 10 because of its noisiness. One discernible pattern in that distribution, however, exhibits velocities lower than $0.01 \mathrm{~m} / \mathrm{s}$ north of $\sim 34^{\circ} \mathrm{S}$ along the northeastern side of the distribution, where high diameter values are observed in Fig. 10b. This suggests that the diameter increase in that area should be ascribed to entrained outer waters, rather than to enlargements of the rings themselves.

Evolutions of diameters and $\mathrm{SSH}$ anomalies as functions of the rings corrected ages, shown in Fig. 11 confirm the slower decrease in diameter. The general decrease of the SSH anomaly resembles 

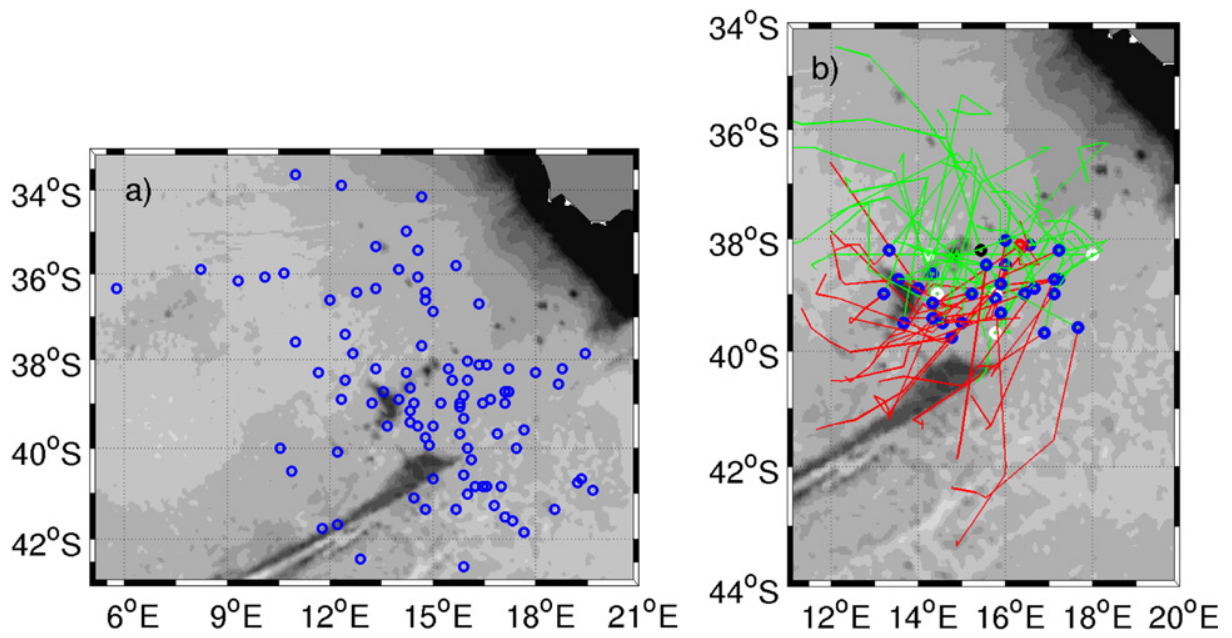

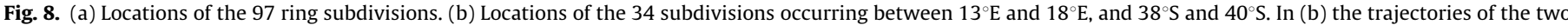

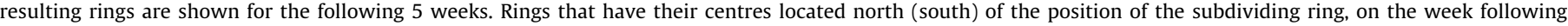
subdivision, are drawn in green (red).
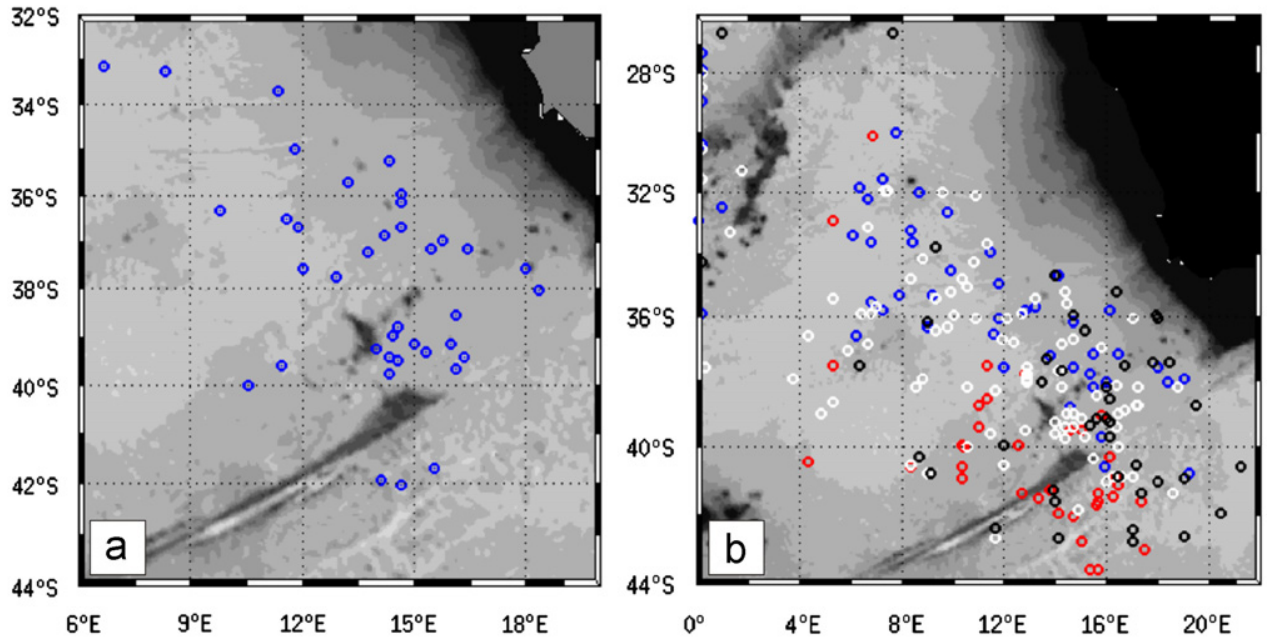

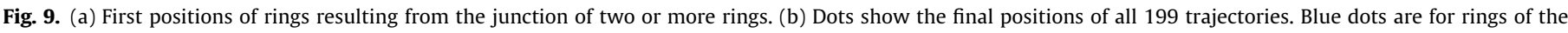

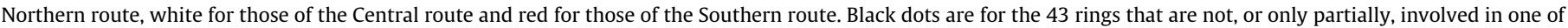
the three routes.

that obtained by Schouten et al. (2000; their Figure 3), but we here have higher initial anomalies $(0.73 \mathrm{~m}$ as compared with $\sim 0.45 \mathrm{~m})$, and a somewhat higher plateau $(0.3 \mathrm{~m}$ as compared with $0.2 \mathrm{~m}$ ) after the decreasing phase. The net average decrease of $\sim 0.43 \mathrm{~m}$ is therefore also higher. These differences probably result from a better spatial resolution of the SSH product used in this study, and from our tracking the Agulhas rings precisely from their formation dates. We also find a faster decay. The SSH anomaly decreases by $50 \%$ within the first 2.5 months against 4 months according to Schouten et al. (2000), probably owing to better detection of ring formation dates, when SSH anomalies are highest and rapidly decreasing.

The mean initial diameter of rings is $240 \mathrm{~km}$, decreasing to about $150 \mathrm{~km}$ before the eddy trajectory ends. The faster decrease in SSH anomaly explains why the wavelet analysis fails to follow the anticyclones any further despite their still significant diameter. Our diameter estimates are on average smaller than those (324 and $240 \mathrm{~km}$ ) obtained by Lutjeharms (1981) and Duncombe Rae (1991). Again, the lower resolution data used in those prior studies probably shifts the detection toward the larger anticyclones.

\section{Defining three Agulhas ring routes}

\subsection{Route definitions}

The analysis of the whole set of ring trajectories has revealed the influence of the bathymetry west of the Agulhas Basin on the rings dynamics. On interacting with bottom topography the rings tend to stall, subdivide into rings with diverging paths, merge with other rings or the retroflection, or dissipate. As the variety of influences rings undergo may dictate their future behaviour and modify their hydrographic properties, these influences could determine the rings contributions to inter-ocean exchanges. Thus, we have searched for different patterns of interaction that could define groups of rings with similar influences. Fig. 4 shows that while some rings drift over these bathymetric elements, others largely avoid topographic influence as they drift either south of the Agulhas Ridge or north of the Erica seamount. Three "routes" thus appear, which are schematically represented in Fig. 12, and named "Northern", "Central" and "Southern routes".

The method adopted to share out ring trajectories among the three routes is based on their trajectories crossing particular 

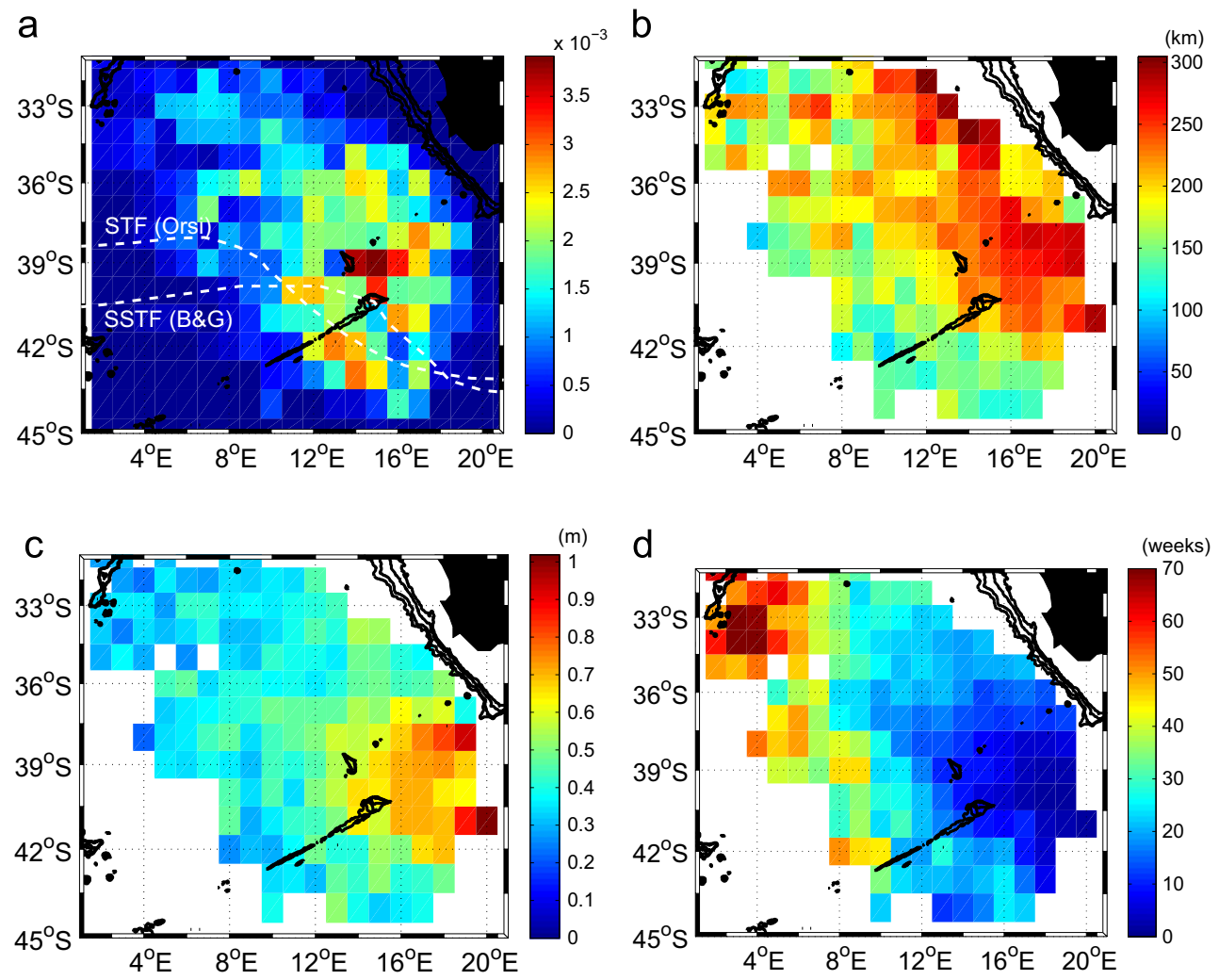

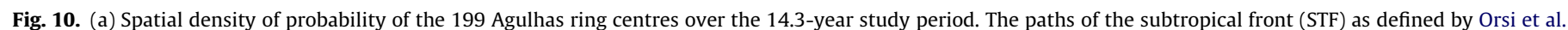

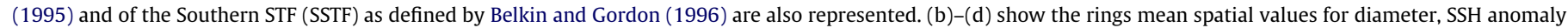

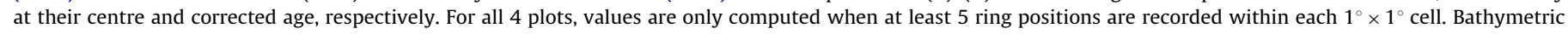
contours are 500, 1000, 2000, and $2500 \mathrm{~m}$.

a

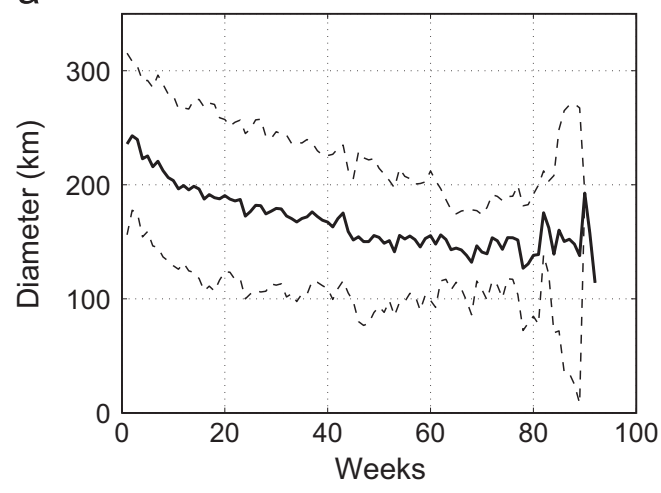

b

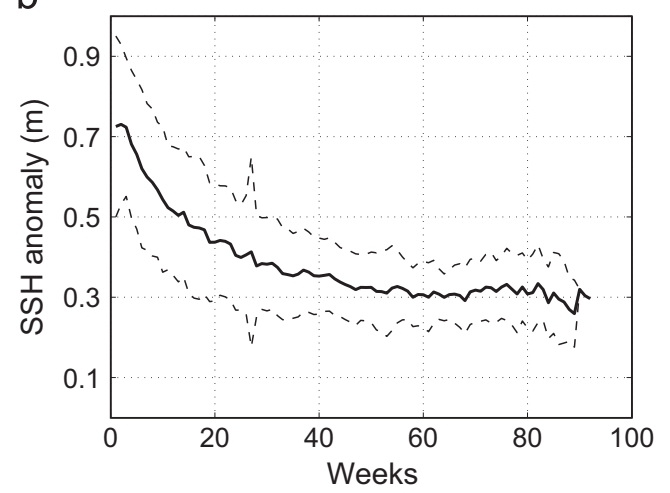

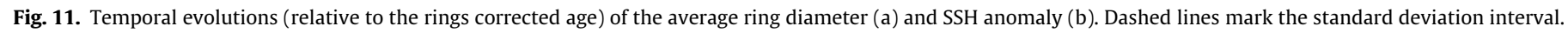

geographical segments. The three segments (Fig. 12) are defined in regard to the Erica seamount and the northeastern end of the Agulhas Ridge. Ring trajectories crossing a segment westward are allocated the corresponding route. Sub-rings issued from a subdivision that occurred to the west of the segments in Fig. 12 are allocated the route of the initial ring they stem from. It must be noted that this method does not allocate a route to every ring trajectory, as some initial rings start to the west of all segments, and other trajectories always remain to their east. When a subring trajectory intersects a segment, the trajectory portion of the initial ring, up to the subdivision date, is also allocated the corresponding route. As the initial ring extension may have taken another route, the starting portion of its trajectory eventually contributes to two routes. From the above considerations we observe that the three routes are neither exactly complementary, as some eddy tracks may escape the classification, nor totally dissociated. This should be kept in mind when estimating the volume transports associated with each route.

A total of 186 trajectories were allocated a route: 59 (32\%) took the Northern route, 90 (48\%) the Central route, and 37 (20\%) the Southern route. We counted 18 trajectories, all initial ones that were not allocated any route. The main statistical parameters of each route are listed in Table 3 . Here below we underline the routes main characteristics and point out specific ring behaviours for each of them.

\subsection{The Northern route}

The trajectories of the rings following the Northern route are represented in Fig. 13 along with the corresponding spatial 
probability distribution of ring positions. The accumulated tracking time of ring trajectories of the Northern route is 1385 weeks, which represents $31.9 \%$ of the total tracking time. This means that, on average, $31.9 \%$ of rings observed at any time in the study area belong to this route.

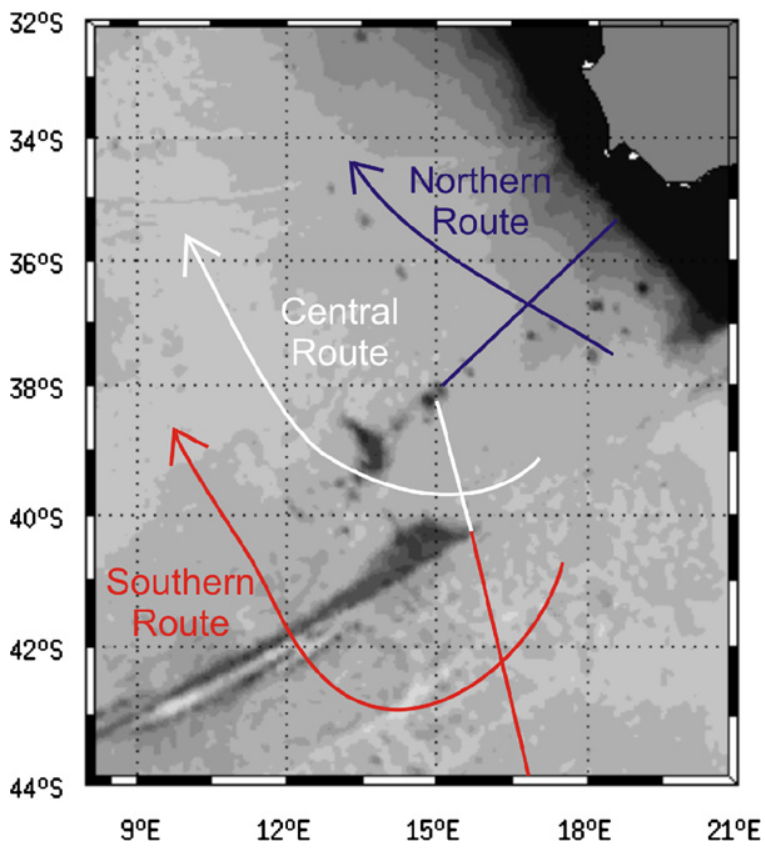

Fig. 12. Schematic representation of the Northern, Central and Southern routes. The coloured segments show the three route definition segments.
A total of 31 Agulhas rings crossed the route definition segment, that is, $27.7 \%$ of all ring passages through the three segments (Table 3 ). This number of rings is lower than the abovequoted number of trajectories belonging to this route (59), because the rings which further subdivide only account for one crossing here. Of these 31 rings, 17 are initial rings that have not subdivided before crossing the segment. This represents $55 \%$ of the Northern route crossings, which is higher than the $37.5 \%$ proportion obtained for the three routes. It reflects a relative easiness for rings of this route to exit the Agulhas Basin as unmodified structures, likely related to the absence of major topographic obstacles northeast of the Erica seamount. The remaining $45 \%$ of rings crossing the segment, however, result from previous splitting mainly caused by interaction with the seamounts farther south. Fig. 8b indeed shows that splitting events near the bathymetry often produce a trajectory branch bypassing the Erica seamount to the north.

While relatively little subject to splitting before exiting the Agulhas Basin, rings of the Northern route seem more prone to subdivision once they have entered the Cape Basin. There, 24 subrings stem from the 31 trajectories that have crossed this route definition segment (in green in Fig. 13a). This yields a "subdivision ratio after crossing" of 0.77 , significantly higher than the 0.47 average ratio over the three routes. This might be due to interactions with the continental slope, as Fig. 8a shows that subdivisions northwest of the route definition segments occur mostly along the African coast in the shallowest part of the Cape Basin. Interactions with the numerous southwestward propagating cyclones originating near the coast, and more generally with the surrounding eddies in this very turbulent region (Boebel et al., 2003; Morrow et al., 2004) is another expected major cause of the high splitting rate.

Table 3

Characteristics of rings of the Northern, Central and Southern routes, and of all routes added together.

\begin{tabular}{|c|c|c|c|c|c|c|c|c|}
\hline \multirow[b]{2}{*}{ Number of route definition segment crossings/\% of the 112 crossings of all three segments } & \multicolumn{2}{|c|}{ Northern route } & \multicolumn{2}{|c|}{ Central route } & \multicolumn{2}{|c|}{ Southern route } & \multicolumn{2}{|c|}{ All routes added } \\
\hline & 31 & $27.7 \%$ & 55 & $49.1 \%$ & 26 & $23.2 \%$ & 112 & \\
\hline Total ring tracking time per route (weeks)/\% of the ring tracking time of all 199 trajectories & 1385 & $31.9 \%$ & 1720 & $39.6 \%$ & 984 & $22.7 \%$ & & \\
\hline Ring life-time, with "corrected age" (weeks) & \multicolumn{2}{|c|}{$24.3($ std $=18.1)$} & \multicolumn{2}{|c|}{$22.3($ std $=18.9)$} & \multicolumn{2}{|c|}{$29.4($ std $=18.5)$} & \multicolumn{2}{|c|}{$24.4($ std $=19.1)$} \\
\hline Number of route definition segments crossings by initial rings/\% of crossings per route & 17 & $55 \%$ & 13 & $24 \%$ & 12 & $46 \%$ & 42 & $37.5 \%$ \\
\hline Subdivision ratio after crossing & 0.77 & & 0.40 & & 0.31 & & 0.47 & \\
\hline \multicolumn{9}{|l|}{ Initial ring never subdividing } \\
\hline Number/\% of definition segment crossings per route & 5 & $16 \%$ & 15 & $27 \%$ & 7 & $27 \%$ & 27 & $24 \%$ \\
\hline Life-time (weeks) & \multicolumn{2}{|c|}{$15.6(\operatorname{std}=13.3)$} & \multicolumn{2}{|c|}{$21.5(\mathrm{std}=22.0)$} & \multicolumn{2}{|c|}{$34.6(\operatorname{std}=14.5)$} & \multicolumn{2}{|l|}{23.8} \\
\hline
\end{tabular}

"Std" stands for standard deviation.

a

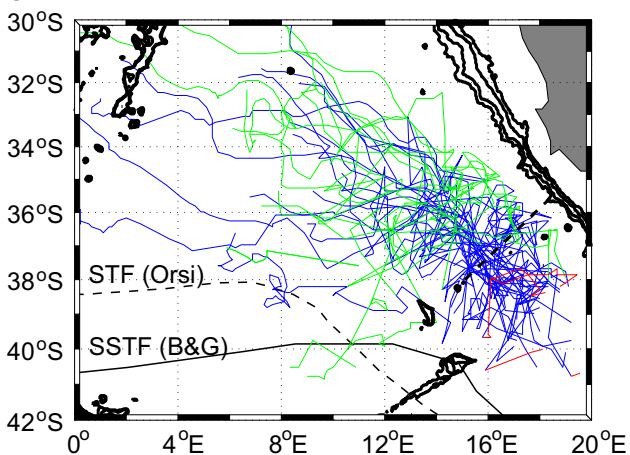

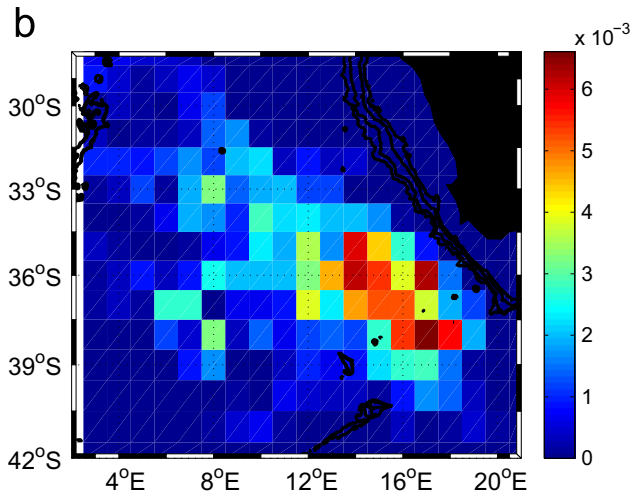

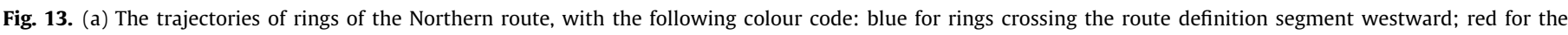

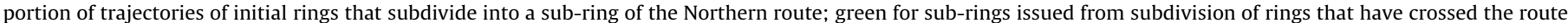
definition segment. (b) Spatial probability distribution of the centres of rings following the Northern route. Bathymetric contours are $500,1000,2000$, and 2500 m. 
4.3. Agulhas rings of the Northern route and the continental slope flow regime

The closeness of some ring trajectories of the Northern route to the African shelf edge, particularly south of $34^{\circ} \mathrm{S}$, implies interactions with the eastern boundary flow regime, which we now illustrate. A first question arises from observations by Lutjeharms et al. (1991) and Duncombe Rae et al. (1992) of a ring drifting near the shelf edge in 1989 that entrained cold water from the coastal upwelling system. Similar observations of rings encountering the continental slope were recently analysed by Baker-Yeboah et al. (2010). The frequency of this phenomenon is largely unknown, yet it could be an important contribution to exchanges between coastal and deep-sea waters. Secondly, measurements across the continental slope near $35^{\circ} \mathrm{S}$ often reveal a northward flowing slope current of Indian Ocean Central Water that is sometimes referred to as the Goodhope Jet (Bang and Andrews, 1974; Gordon et al., 1995; Gladyshev et al., 2008). However, whether this current is a partial, possibly nonpermanent, extension of the Agulhas Current into the Atlantic Ocean, whose existence is suggested by surface drifters and subsurface floats trajectories (Richardson, 2007) and by some model studies (Doglioli et al., 2006), or whether it is the signature of the anticyclonic circulations associated with frequent passages of Agulhas rings along the continental slope, remains unclear. The frequent presence of cyclonic eddies against the continental slope in this region (Penven et al., 2001) makes the issue still more complicated. What part rings from the Northern route could play in both cases depends on their statistical rate of presence along the shelf. We thus define an "interaction rate" of rings along the African shelf as the percentage of the time series length during which a ring interacts with the continental slope regime.

To determine if a ring interacts with the continental slope regime, we somewhat arbitrarily consider that a ring influence is felt at a distance of $150 \%$ of its mean radius (determined from the surface enclosed within its often non-circular contour). If the ring centre is less than this distance from the $500 \mathrm{~m}$ bathymetric contour of the shelf, we consider that the ring is interacting with the flow regime at the continental slope. As the shelf is steep in this region, choosing another bathymetric contour yields nearly identical results. On the other hand, results varied when choosing another distance criteria. The 50\% increase of the ring radius, an admittedly arbitrary choice, roughly accounts for water entrainment in the ring periphery beyond its own dynamical contour (McCartney and Woodgate-Jones, 1991).

We found that 13 rings interacted with the shelf for an accumulated 110 -week period. The mean interaction time per ring is 8.5 weeks. As the total study period is 743 weeks, the "interaction rate" is $14.8 \%$. The 13 ring trajectories are shown in Fig. 14a, with an indication of the positions of interaction (bold segments), all located south of $34^{\circ} \mathrm{S}$. The interaction rate, even though a much uncertain estimate, seems too small to credit the rings with the frequent northward flow along the continental shelf, more likely suggesting the added contribution of a current. However, this interaction rate is significant enough to allow entrainment of coastal waters on a regular basis. An illustration of the way a ring along the African shelf can entrain water in its rotation is shown in Fig. 14b from the trajectory of a profiler from the international Argo program. As these profilers drift at intermediate levels (here $1000 \mathrm{~m}$ depth) for 10-day periods, at which intervals they pop up to the surface to send the recorded data via satellite, the displayed trajectory looks like a broken line. It nevertheless appears that this float (Argo number 1900467), which was moving southward off the continental shelf in 2006, encountered one of the 13 rings we identified. It then performed two anticyclonic rotations around the ring, closely approaching the edge of the continental shelf, before proceeding southward.

\subsection{The Central route}

The Central route is characterised by rings drifting between the Erica seamount and the northern end of the Agulhas Ridge. The trajectories of all rings involved in this route are represented in Fig. 15a. There are 55 crossings of the route definition segment, $49.1 \%$ of the total eddy crossings for the three routes, making the Central route the preferred one. Out of the 55 crossings, 13 are by initial rings that have not previously subdivided. This represents only $24 \%$ of the crossings, well below the $37.5 \%$ over the three routes. This observation that rings of the Central route have often been previously involved in a subdivision should be related to the high concentration of subdivision locations near the bathymetry west of the Agulhas Basin (Fig. 8a). As this figure shows that some a

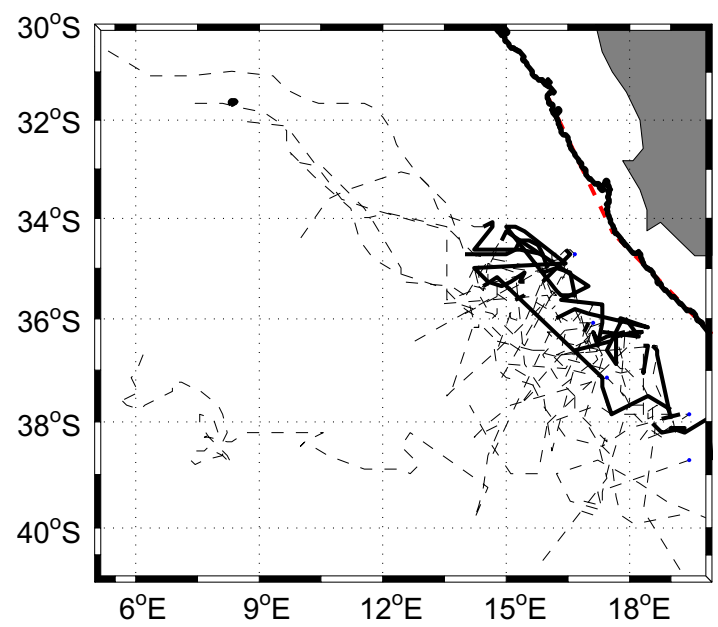

b

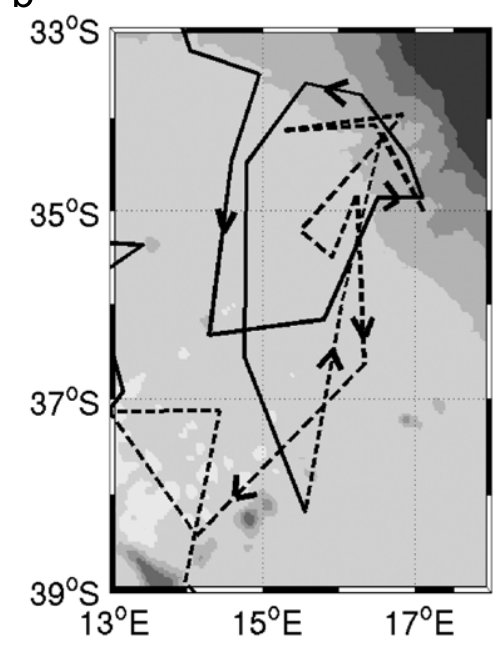

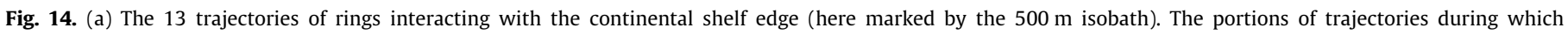

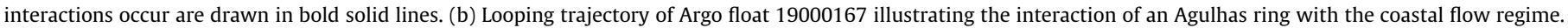
Two line styles (solid, then dashed) are used to make the float path clearer to the eye. 

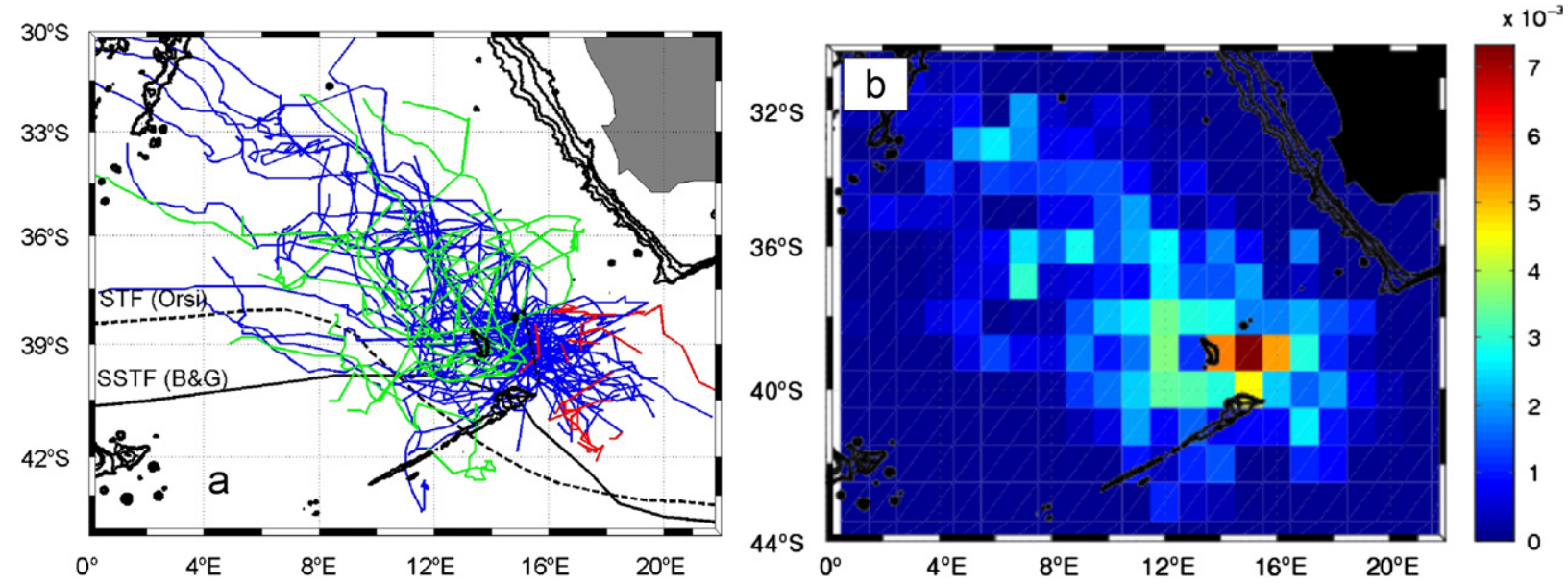

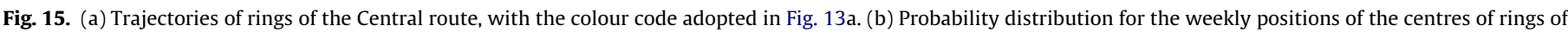
the Central route. Bathymetric contours are 500, 1000, 2000, and $2500 \mathrm{~m}$.
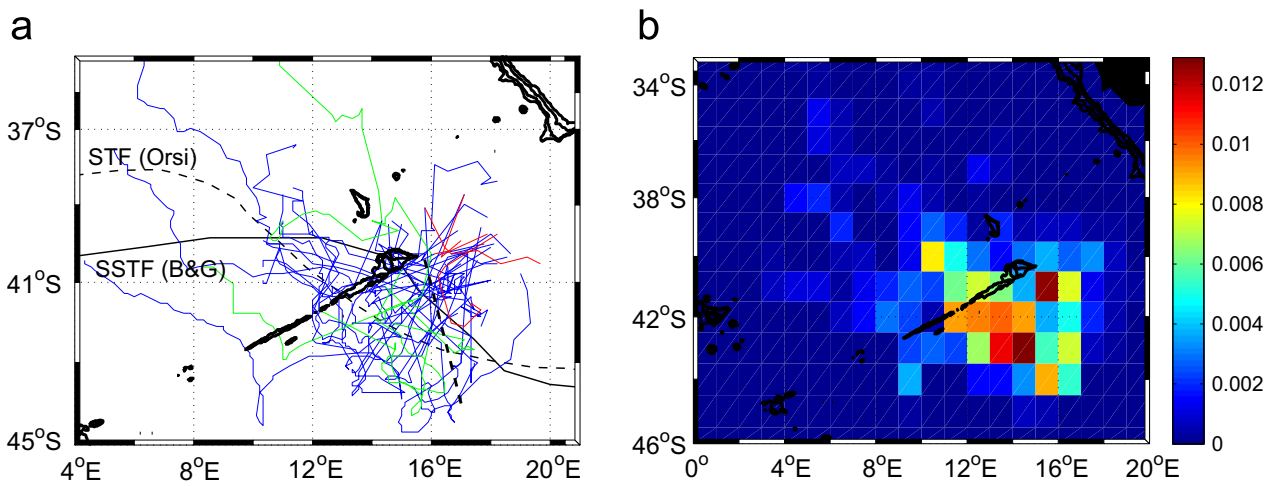

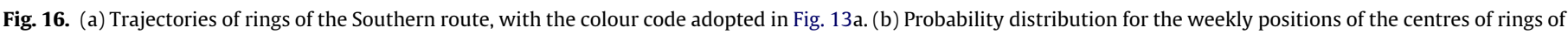
the Southern route. Bathymetric contours are 500, 1000, 2000 and $2500 \mathrm{~m}$.

subdivisions occur near the Schmitt-Ott seamount, west of the definition segment of the Central route, the percentage of rings of the Central route moving past the three bathymetric elements without subdividing is actually even lower than $24 \%$. The probability of presence shown in Fig. 15b exhibits its maximum (already mentioned from Fig. 10a) in the area bordered by the Erica seamount to the north, the Schmitt-Ott seamount to the west, and the Agulhas Ridge to the south. As no particular ageing of the eddies across these obstacles appears in Fig. 10d, the high concentration of trajectories, rather than eddy stalling, should be the main cause of the high probability spot in Fig. 15b.

We mentioned above (Fig. 8b) the diverging paths resulting from eddy subdivisions east of the three obstacles. Fig. 15b, exhibiting weak rates of presence above and west of the SchmittOtt seamount, and higher probabilities north and south of it in the passages formed by the seamount and the two neighbouring obstacles, suggests that similar splitting/diverging rings behaviours occur near this particular seamount.

After crossing the definition segment of the Central route, 22 sub-rings form from subdivisions of some of the 55 initial rings (green trajectories in Fig. 15a). The "subdivision ratio after crossing" along this route is therefore $40 \%$, only slightly lower than the total average of $47 \%$.

The accumulated tracking time of trajectories of this route is 1720 weeks, corresponding to $39.6 \%$ of the tracking time for all three routes. This fraction being lower than the percentage of crossings of the route definition segment, results in a corrected life duration of eddies of the Central route (22.3 weeks) lower than the average life duration for all routes ( 24.4 weeks). From the above, this might be a consequence of the high subdivision rate east of the bathymetry, but also of a likely erosion of the rings deep layers by the obstacles.

Past the Schmitt-Ott seamount, rings adopt a northwestward drift, including those that have drifted south of the seamount. As a result, nearly all trajectories remain to the north of the line marking the climatological Subtropical Front (STF, Orsi et al., 1995) or South Subtropical Front (SSTF, Belkin and Gordon, 1996), not penetrating the colder subantarctic waters south of the STF (Fig. 15a). From Fig. 15a, the climatological SSTF tracks even appear as an approximate southern limit for the ring trajectories in the $10^{\circ} \mathrm{E}-14^{\circ} \mathrm{E}$ longitude band. This corroborates the fact that SSTF detection according to water property criteria (e.g. Orsi et al., 1995) in hydrological sections often located it at the southern flank of propagating Agulhas rings (Lutjeharms and Van Ballegooyen, 1988; Arhan et al., 1999; Gladyshev et al., 2008). The Agulhas rings of the Central route might therefore take an important part in the setting up of the SSTF climatological track.

\subsection{The Southern route}

Rings of the Southern route, as can be seen from their trajectories in Fig. 16a, all drift south of the Agulhas Ridge, into the subantarctic waters south of the STF. There they were shown to undergo intense hydrologic modifications through mixing and air-sea exchanges (e.g. Gladyshev et al., 2008). As compared with the two other routes both located in the subtropical domain, this 
a

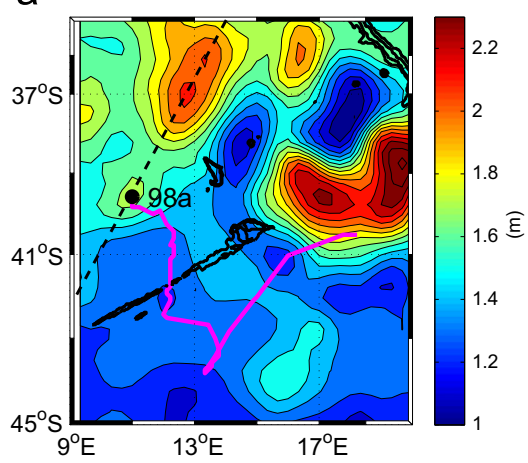

b

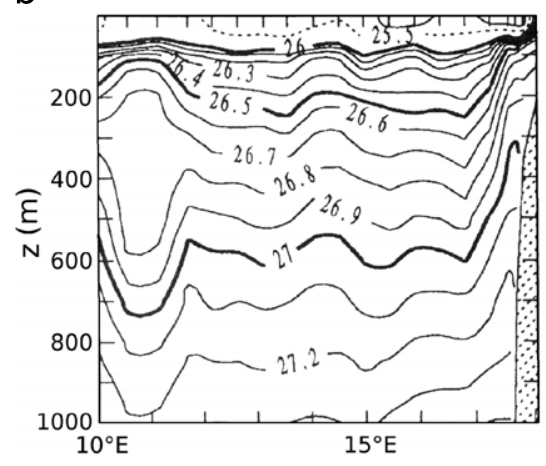

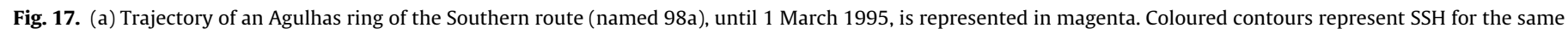

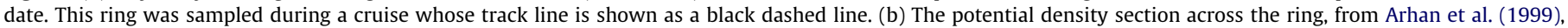
shows the ring homogenised and deep core.

Southern route should therefore contribute differently to IndoAtlantic exchanges. Lutjeharms and Valentine (1988) described anticyclones also containing subtropical water from the South Indian Ocean that enter the subantarctic domain south of the Agulhas Return Current. The Southern route vortices described here should be related to their "warm eddies" category formed in the vicinity of the Agulhas Current retroflection. While Lutjeharms and Valentine (1988) mostly focused on those eddies which are either dissipated in the subantarctic domain or re-injected in the Agulhas Return Current, we here have evidence that a part of these vortices eventually move northwestward through the Southern route definition segment toward the south Atlantic.

Hydrologic specificities of these rings were described by Arhan et al. (1999) and Gladyshev et al. (2008): Most noticeable, intense air-sea heat transfers and associated near-surface lateral exchanges with subantarctic surrounding waters (Donners et al., 2004) lead to deep convection and cooling within the cores of these anticyclones. The trajectory of the ring studied by Arhan et al. (1999), identified in this study, and its measured potential density as it was intercepted north of the Agulhas Ridge, are shown in Fig. 17. The vertical homogeneity of the eddy core in the density section signals recent convection.

The Southern route is the one least taken by rings, as there are 26 crossings of the route definition segment, representing only $23.3 \%$ of crossings of all three route segments (Table 2). Of these crossings, 12 are by initial rings that have not subdivided previously, amounting to $46 \%$ of the route segment crossings. This is significantly higher than the $37.5 \%$ value for all three routes. The $54 \%$ other crossings for the Southern route are by rings that have subdivided near the bathymetry to the west of the Agulhas Basin, particularly at the Agulhas Ridge northern end. Fig. 8b illustrating these splitting events does show some trajectories entering the Southern route.

As the rings move south of the Agulhas Ridge, most of them stall there for some time before eventually crossing the obstacle northwestward, explaining the high statistical presence south of the Ridge (Fig. 16b). Although the rings undergo intense cooling in this region, their mean life-time of 29.4 weeks is the longest of all routes, and is 5 weeks longer than the average for all routes. The intense hydrological modifications of the rings, although certainly contributing to their erosion, do not impact on their overall life duration. This should be partly explained by the fact that few of these rings subdivide after crossing the definition segment. Indeed, only 8 sub-rings are formed west of the segment, yielding a $31 \%$ "subdivision ratio after crossing", the lowest of all routes. Unlike rings of the two other routes, rings stalling south of the Agulhas Ridge are not submitted to interactions with the intense mesoscale activity of the Cape Basin north of the ridge, which also explains their longer life-time.

Roughly half of the rings of the Southern route manage to cross the Agulhas Ridge - as indicated by their final positions (Fig. 9b) and contribute to Indo-Atlantic exchanges. We should note, however, that the cooling of their cores and the ensuing geostrophic adjustment leading to lens-shaped structures (Fig. 17b) accelerate the disappearance of their surface altimetric signatures. How much of the low ratio of apparent ridge crossings is due to real ring dissipation, and how much is due to a decrease in SSH signature is unclear. Rings crossing the ridge are then rarely tracked any further north than $38^{\circ} \mathrm{S}$, and their trajectories are mostly confined to the south of the SSTF (Fig. 16a). Our inability to track these rings north of the STF might also not be due to ring dissipation, but to subduction below the warmer surface waters of the subtropical region. As they subduct, the rings lose their SSH anomaly signature, and cannot be tracked using the wavelet analysis. The dynamics of this phenomenon were studied by Herbette et al. (2004). The ring trajectories of the Southern route, particularly of those that have crossed the Agulhas Ridge northwestward and possibly subducted at the STF, are therefore probably interrupted before the actual dissipation of the vortices. This effect is likely more important for the Southern route than for the other two routes.

\section{Comparing the routes - volume transport estimates}

The three routes here defined were introduced - somewhat artificially - by considering the obstacles facing the Agulhas rings at their entry in the South Atlantic. Those of the Central and Southern routes face bathymetric obstacles, yet of different kinds, seamounts (reaching up to $\sim 1300 \mathrm{~m}$ depth) separated by narrow passages for the former, and a deep bathymetric barrier for the latter. Those of the Northern route do not encounter any significant bathymetric obstacle, yet the time-averaged $\mathrm{SSH}$ distribution (e.g., Fig. 2 of Dencausse et al., 2010) reveals the frequent presence of cyclonic eddies in the passage northeast of the Erica seamount. These - the so-called lee eddies of Penven et al., 2001 - likely impede the northwestward advance of the rings, and might be the reason why the Northern route is less taken than the Central one. The above descriptions of the rings behaviour show that these different obstacles at the entry of the South Atlantic not only contribute to share out the rings among the three routes, but also lead to different characteristics of their trajectories, in terms of splitting and merging events.

Other differences, not observed from $\mathrm{SSH}$, add to these ones to make the three routes more than just a matter of classification. 

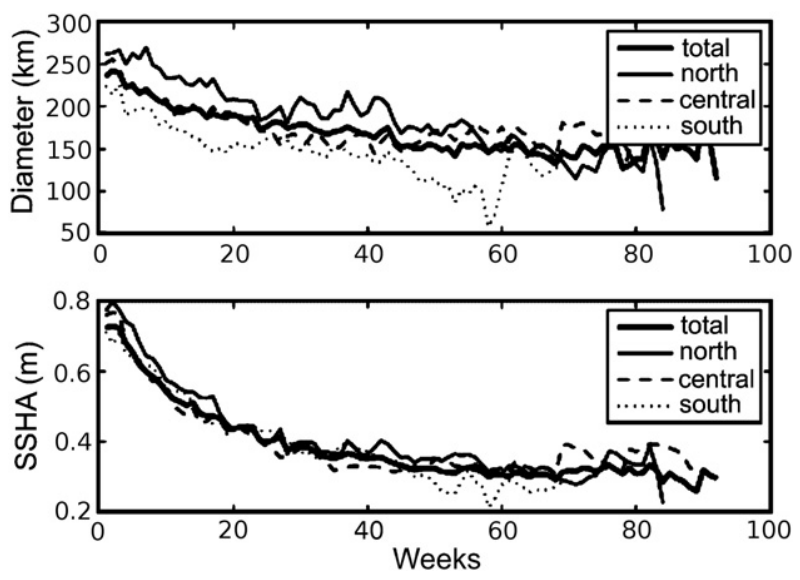

Fig. 18. Temporal evolutions of rings mean diameter (upper) and SSH anomaly (lower) at the eddy centres. Ring ages are corrected ages (see text).

These refer to the different air-sea exchanges, and different water mass environments by the rings along these routes, which in turn affect their core properties. Arhan et al. (1999) observed three Agulhas rings in the Cape Basin, which happened to belong to each of the three routes. Their ring R1 from the Southern route (the one shown in Fig. 17) had a core temperature of $11.5^{\circ} \mathrm{C}$. Their ring $\mathrm{R} 2$, on the other hand, had kept a temperature $\left(17.1^{\circ} \mathrm{C}\right)$ close to that of the South Indian Central Water, having escaped the retroflection region rapidly through the Northern route. Finally, their ring R3 from the Central route had a temperature of $13.5^{\circ} \mathrm{C}$, the likely result of its stalling close of the Schmitt-Ott seamount during the winter season. Although this particular temperature gradation should not be generalized, as property alterations also depend on the spawning season and on the time spent at high latitudes, it illustrates the effects the routes may have on the water properties injected in the Atlantic Ocean.

As further illustration of differences between the routes, Fig. 18 exhibits the time evolutions of ring diameters and $\mathrm{SSH}$ anomalies for each route. The age used is the rings corrected age. It appears that the largest rings are found in the Northern route, the smallest in the Southern route. Fig. 18a shows, however, that the Northern route average diameter stabilizes at 20-40 weeks, the same ages as observed at $32^{\circ} \mathrm{S}-34^{\circ} \mathrm{S}$ along the African continental slope, where we suggested that entrainment of neighbouring water by the rings could be the reason for their increased size. The evolutions of SSH anomalies exhibit smaller differences between routes. The initial diameters for the Northern and Central route are both around $250-260 \mathrm{~km}$. However, diameters for the Central route decrease sharply during the first three weeks, as a result of the subdivisions near the Agulhas Ridge and nearby seamounts. The diameters of rings of the Southern route decrease during the first 17 weeks, but then stabilise during their blocking south of the Agulhas Ridge, as they do not undergo any subdivisions or interactions with mesoscale features (Fig. 18a). The SSH anomalies decrease more steadily, this parameter proving to be a better indicator of a ring's age, regardless of the route it takes.

\subsection{Volume transport estimates by the three routes}

The entrainment of Indian Ocean subtropical water into the Atlantic Ocean, often termed the Agulhas leakage, is generally viewed as the result of several mechanisms, namely, the westward motions of Agulhas rings, of cyclones (Boebel et al., 2003), of filaments (Lutjeharms and Cooper, 1996), and a possible partial extension of the Agulhas Current (the Good Hope Jet) along the south African continental slope (Gordon et al., 1995). The volume transport estimates of these various contributions to the Agulhas leakage still have large uncertainties. That of the Agulhas rings, however, is undoubtedly significant, and was sometimes thought dominant. de Ruijter et al. (1999) reported previous estimates of it ranging from 3 to $9 \mathrm{~Sv}$, and Richardson (2007), drawing on Schouten's et al. (2000) result that about 8 rings (including sub-rings) are formed each year, each conveying 1.31.6 Sv, estimated a ring contribution of $10-13 \mathrm{~Sv}$ to the Agulhas leakage. Previous studies often base their calculations on either a fixed number of rings drifting into the Atlantic Ocean per year, or a fixed volume transport per ring. However, our study has shown the difficulty of counting rings drifting into the Atlantic, as 102 initial rings shed at the retroflection eventually lead to 199 ring trajectories through subdivisions and junctions. Moreover, while some rings are tracked well into the Cape Basin, others dissipate near the Agulhas retroflection or are reabsorbed by the retroflection, therefore not contributing to inter-ocean exchanges. Thus, the choices of the number of rings entering the Atlantic Ocean and of a section through which their transport is evaluated are highly interdependent. Also, the dissipation of rings as they drift into the Atlantic ocean, as well as the high variability observed in their diameters, makes it difficult to fix a volume transport per ring. As this study has produced the trajectories of all rings issued from the Agulhas Current retroflection, we may evaluate their net volume transport through several sections of the southeastern Atlantic Ocean without any assumption concerning their number. Moreover, the decrease in diameters obtained in our study, though not firmly related to the trapped areas proper, is an indication of the rings gradual dissipation. These diameters at least provide weekly values that can be used to evaluate individual and time-dependent rings volumes without having to fix an a priori single value.

We defined a set of sections perpendicular to the general drift direction of rings, labelled (a)-(f), through which the Agulhas rings transport was calculated (Fig. 19). Sections (a) and (b), closest to the retroflection region, only differ in their southernmost segment. As many ring trajectories of the Southern route end south of the Agulhas Ridge, we expect a sharp decrease in transport values for this route between those two sections, but identical values for the other two routes. To calculate the transport of a ring as it crosses a section, we multiply its diameter by a standard $1000 \mathrm{~m}$ depth. Westward crossings are counted positively, eastward crossings negatively.

Hypothesizing that Agulhas rings trap water down to a constant depth of $1000 \mathrm{~m}$ is also admittedly a rough makeshift reflecting our lack of knowledge regarding this parameter and its time evolutions. Hydrological observations of rings near the southeastern border of the Cape Basin suggested trapping depths exceeding $1000 \mathrm{~m}$ (e.g. Gladyshev et al., 2008), and Schmid et al. (2003), using velocity measurements from acoustic doppler current profilers and RAFOS floats even found a value in excess of $1600 \mathrm{~m}$ for a juvenile ring. When observed 7 months later in the central Cape Basin, the same ring had experienced strong mixing beneath $800 \mathrm{~m}$. Donners et al. (2004) inferring the residence times of particles within a modelized Agulhas ring from a Lagrangian particle tracer technique, found values over 6 months down to about $1200 \mathrm{~m}$, and one year down to $800 \mathrm{~m}$. The shoaling of the trapping depth with time, however, is likely not monotonous, as this depth depends on the ring swirl and phase velocity ratio (Flierl, 1981), and may sharply decrease at the early stages of a ring life, when interactions with neighbouring structures in the energetic southeastern Cape Basin temporarily accelerate the eddy displacements. Interaction with the bathymetry along the Central and Southern routes is another likely cause of early decrease of the trapping depths. Because of the high 

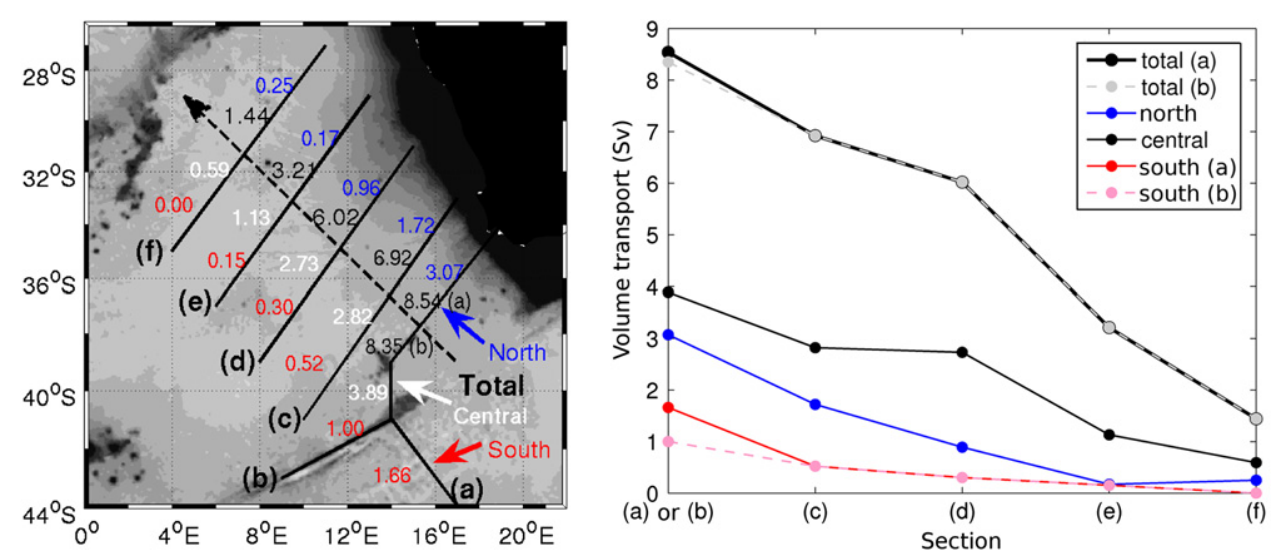

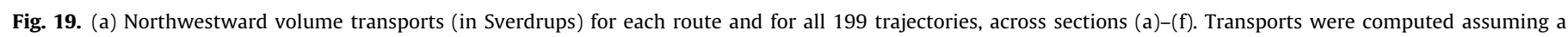

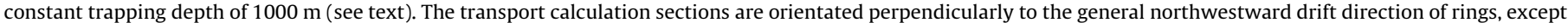

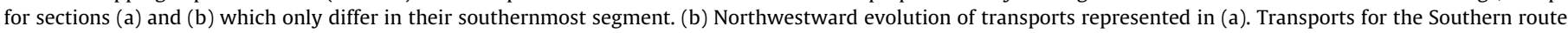

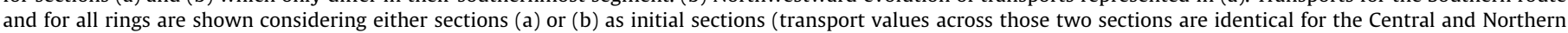
routes).

Table 4

Ring transports across sections (a)-(f) of Fig. 19, for all 199 ring trajectories, for the Northern, Central and Southern route, and for the routes added together.

\begin{tabular}{|c|c|c|c|c|c|c|c|c|c|c|c|c|c|c|c|}
\hline & \multicolumn{3}{|c|}{ All 199 trajectories } & \multicolumn{3}{|c|}{ Northern route } & \multicolumn{3}{|c|}{ Central route } & \multicolumn{3}{|c|}{ Southern route } & \multicolumn{3}{|c|}{ All routes } \\
\hline & Wwrd & Ewrd & net & Wwrd & Ewrd & net & Wwrd & Ewrd & net & Wwrd & Ewrd & net & Wwrd & Ewrd & net \\
\hline Section (a) & 12.0 & 3.0 & 8.5 & 4.4 & 1.3 & 3.1 & 4.9 & 1.0 & 3.9 & 2.1 & 0.4 & 1.7 & 11.4 & 2.8 & 8.6 \\
\hline Section (b) & 11.2 & 2.9 & 8.4 & 4.4 & 1.3 & 3.1 & 4.9 & 1.0 & 3.9 & 1.2 & 0.2 & 1.0 & 10.5 & 2.6 & 8.0 \\
\hline Section (c) & 8.6 & 1.7 & 6.9 & 2.9 & 1.1 & 1.7 & 3.4 & 0.6 & 2.8 & 1.1 & 0.6 & 0.5 & 7.4 & 2.3 & 5.1 \\
\hline Section (d) & 6.4 & 0.4 & 6.0 & 1.2 & 0.3 & 0.9 & 2.7 & 0 & 2.7 & 0.6 & 0.3 & 0.3 & 4.5 & 0.6 & 3.9 \\
\hline Section (e) & 3.2 & 0 & 3.2 & 0.2 & 0.02 & 0.2 & 1.1 & 0 & 1.1 & 0.3 & 0.1 & 0.2 & 1.6 & 0.1 & 1.5 \\
\hline Section (f) & 1.6 & 0.1 & 1.4 & 0.3 & 0 & 0.3 & 0.7 & 0.1 & 0.6 & 0 & 0 & $\mathbf{0}$ & 1.0 & 0.1 & 0.8 \\
\hline
\end{tabular}

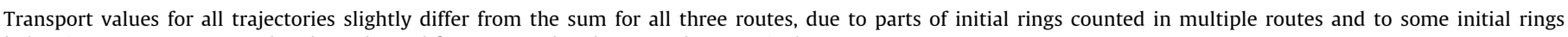
belonging to no route. Wwrd and Ewrd stand for westward and eastward, respectively.

variability of these interactions, we settled for a standard depth for all rings. This may lead to slightly underestimate the transports through the easternmost sections and overestimate them through the westernmost sections. The latter effect, however, is probably somewhat compensated, as rings are not tracked until full dissipation, and the trajectories often end east of the westernmost transport calculation sections. The retained value of $1000 \mathrm{~m}$ for the trapping depth falls within the range of available estimates (Duncombe Rae et al., 1996; Schmid et al., 2003).

The transports obtained for sections (a) through (f) are indicated in Fig. 19 for all 199 trajectories and each route. Transports are also indicated in Table 4, along with eastward and westward transports through each section. The maximum total transport is $8.5 \mathrm{~Sv}$ through section (a), on the high side of the 3-9 Sv range quoted by de Ruijter et al., 1999, but lower than the 10-13 Sv proposed by Richardson (2007). The total transport decreases westward, with only a $30 \%$ decrease through section (d), and a sharper decrease onward with only $1.4 \mathrm{~Sv}$ crossing section (f). The gradual decrease of the total transport reflects the dissipation of rings, whose water of Indian Ocean origin is mixed in with the surrounding waters of the Cape Basin. These results show the importance of specifying calculation sections for the rings transport estimates into the Atlantic Ocean.

The Central route contributes half the ring transport estimates through most sections, in keeping with the $49.1 \%$ of crossings for this route definition segment. This route also clearly displays the slowest westward transport decrease, with only a $30 \%$ decrease between sections (a) and (d), compared to $71 \%$ and $82 \%$ for the Northern and Southern routes, respectively. This is mainly explained by the comparatively high northwestward drift speed of rings of the Central route west of the bathymetry separating the Agulhas and Cape basins: since all routes have similar time evolutions of ring diameters (see Fig. 18), the fast drifting rings of the Central route reach the westernmost transport calculation sections with relatively large diameters, accounting for the important transports through section (d). The Northern route is the second contributor to ring transport. The Southern route contributes a still weaker fraction of the total transport, with only $1.66 \mathrm{~Sv}$ through section (a). Its transport sharply decreases through section (b) due to many trajectories ending south of the Agulhas Ridge.

\section{Conclusions}

Using time series of weekly maps of absolute SSH, we have studied the Agulhas rings displacements and evolutions over a period of 14.3 years, right from their spawning dates at the Agulhas Current retroflection, and throughout the Cape Basin. The wavelet analysis used to follow the rings allowed us to detect and take into account ring subdivisions and junctions. The trajectories exhibit a general northwestward direction within a domain that extends farther south than the corridor proposed by Garzoli and Gordon (1996) and, to a lesser extent, the Cape Cauldron area of Boebel et al. (2003). The space-time evolutions of ring characteristics show a faster decrease of SSH anomalies than of diameters. Although 102 rings were spawned at the retroflection during the study period, 199 trajectories were identified due to ring subdivisions and junctions, an illustration of the trickiness of 
counting Agulhas rings. These numbers also gauge the variety of interactions undergone by rings in the highly turbulent southeastern Cape Basin (Boebel et al., 2003), either mutual interactions, or with the surrounding cyclones, or with the bathymetry.

Despite the high turbulence, the length of the study period and the high number of detected rings have allowed us to discern different characteristics of the rings along three main paths determined by the Erica and Schmitt-Ott seamounts and the northeastern tip of the Agulhas Ridge. These obstacles influence the ring behaviours, impeding their westward drift and often causing them to subdivide into rings with diverging northward and southward drift directions. Nearly half of the Agulhas rings travel between the Erica seamount and northern tip of the Agulhas Ridge, taking the "Central route". An important number also travel north of the Erica seamount along the "Northern route", while a smaller fraction take the "Southern route" south of the Agulhas Ridge and through the subantarctic area.

Although 55\% of rings taking the Northern route have not undergone previous subdivisions, many subdivisions are recorded in the subsequent part of the rings path through Boebel's et al. (2003) Cape Cauldron, a behaviour certainly favoured by the numerous newly formed cyclones present there. The interactions of rings of the Northern route with the continental slope flow regime seem frequent enough to induce significant entrainment of cold water from the Benguela upwelling system to the ocean interior, but not frequent enough to solely account for the frequent presence of a northward along-slope current at the shelf edge.

Three quarters of rings taking the Central route have previously subdivided through their interactions with the bathymetry. The divergence of trajectories after subdivision causes rings to by-pass the Schmitt-Ott seamount either to the north or to the south. Past the seamount, rings resume a particularly swift northwestward drift, never penetrating the subantarctic waters south of the Subtropical front. The southernmost trajectories of this route could even play a role in the constitution of the front, which has regularly been measured on the southern flank of rings at this location. Few subdivisions are recorded west of the Schmitt-Ott seamount, as rings drift in the deeper parts of the Cape Basin.

Although only a quarter of Agulhas rings take the Southern route, their contribution to inter-ocean exchanges in terms of water property will probably be different from that of the other routes. Our analysis revealed a tendency of the rings of the Southern route to stall south of the Agulhas Ridge, and previous studies have shown that this may cause significant cooling and homogenization of their core waters through intense air-sea exchanges and resulting vertical convection. In this region, however, they do not experience much interaction with mesoscale features, explaining the few recorded subdivisions. Although their cooling rapidly diminishes their SSH anomaly signature, sometimes resulting in premature interruptions of their tracking, rings of the Southern route have the longest recorded life-times, a likely consequence of their avoiding the turbulent Cape Basin. The rings that manage to cross the Agulhas Ridge then rapidly lose their SSH anomaly signatures as they subduct under the warmer surface waters north of the STF.

We have attempted an evaluation of the transport of Indian Ocean water by the Agulhas rings, using their variable estimated diameters and a constant $1000 \mathrm{~m}$ depth for all rings. This undoubtedly results in large uncertainties, given the loose relation between the wavelet-induced ring areas and the areas of water trapping. The constant trapping depth is itself a bold hypothesis. Such computations nevertheless provide an idea of the transport decrease through the Cape Basin, and of the relative contributions of the three routes. The total transport decreases from an initial value of $8.5 \mathrm{~Sv}$ near the Agulhas Current retroflection, to $\sim 1.4 \mathrm{~Sv}$ in the northwestern Cape Basin. The Central route is the main contributor to these transports, with the Northern route a close second. The Southern route contributes little, yet the accelerated erosion of the rings surface signatures along this route pleads for an underestimation of their contribution. The dominant contribution of the Central route over the Northern route, both in terms of ring numbers and water transport, is surprising, given the bathymetric obstacles associated with the former. As a possible explanation to this observation, we noted that the entry of the Northern route is itself often occupied by cyclonic structures formed west of the Agulhas Bank (Penven et al., 2001), which might constitute a still more efficient obstacle than the seamounts of the Central route, and perhaps divert the paths of some rings toward the latter. A closer examination of such behaviours would require a dedicated analysis.

\section{Acknowledgements}

This contribution to the CLIVAR/GoodHope program was supported by the IFREMER program "Circulation Océanique", by INSU (Institut National des Sciences de l'Univers), the CNRS, and the Université de Bretagne Occidentale. G. Dencausse's contribution was done while a student at the Laboratoire de Physique des Oceans, supported by a grant from the Ecole Normale Supérieure. We wish to thank Bruno Blanke and Andrea Doglioli for useful discussions and advices about using the wavelet analysis for tracking eddies in the Cape Basin. We are also thankful to Dr. Erik van Sebille and an anonymous reviewer for their comments which significantly improved the manuscript.

\section{References}

Arhan, M., Mercier, H., Lutjeharms, J.R.E., 1999. The disparate evolution of three Agulhas rings in the South Atlantic Ocean. Journal of Geophysical Research 104 (C9), 20987-21005

Baker-Yeboah, S., Flierl, G.R., Sutyrin, G.G., Zhang, Y., 2010. Transformation of an Agulhas eddy near the continental slope. Ocean Sciences 6, 143-159.

Bang, N.D., Andrews, W.R.H., 1974. Direct current measurements of a shelf-edge frontal jet in the southern Benguela system. Journal of Marine Research 32 405-417.

Belkin, I.M., Gordon, A.L., 1996. Southern Ocean fronts from the Greenwich meridian to Tasmania. Journal of Geophysical Research 101 (C2), 3675-3696.

Biastoch, A., Krauss, W., 1999. The role of mesoscale eddies in the source regions of the Agulhas Current. Journal of Physical Oceanography 29 (9), 2303-2317.

Boebel, O., Lutjeharms, J.R.E., Schmid, C., Zenk, W., Rossby, T., Barron, C., 2003. The Cape Cauldron: a regime of turbulent inter-ocean exchange. Deep-Sea Research II 50 (1), 57-86.

Byrne, D.A., Gordon, A.L., Haxby, W.F., 1995. Agulhas eddies-a synoptic view using Geosat ERM data. Journal of Physical Oceanography 25 (5), 902-917.

Clement, A.C., Gordon, A.L., 1995. The absolute velocity-field of Agulhas eddies and the Benguela Current. Journal of Geophysical Research 100 (C11), 22591-22601.

Dencausse, G., Arhan, M., Speich, S., 2010. Spatio-temporal characteristics of the Agulhas Current retroflection. Deep-Sea Research I, this issue, doi:10.1016/ j.dsr.2010. 07.004.

Duncombe Rae, C.M., Shillington, F.A., Agenbag, J.J., Taunton-Clark, J., Gründlingh, M.L., 1992. An Agulhas ring in the South Atlantic ocean and its interaction with the Benguela upwelling frontal system. Deep-Sea Research, 39, 2009-2027.

Duncombe Rae, C.M., Garzoli, S.L., Gordon, A.L., 1996. The eddy field of the southeast Atlantic ocean: A statistical census from the Benguela Sources and Transport Project. Journal of Geophysical Research, 101, 11949-11964.

de Ruijter, W.P.M., Biastoch, A., Drijfhout, S.S., Lutjeharms, J.R.E., Matano, R.P., Pichevin, T., van Leeuwen, P.J., Weijer, W., 1999. Indian-Atlantic interocean exchange: dynamics, estimation and impact. Journal of Geophysical Research 104 (C9), 20885-20910.

Doglioli, A.M., Blanke, B., Speich, S., Lapeyre, G., 2007. Tracking coherent structures in a regional ocean model with wavelet analysis: application to Cape Basin eddies. Journal of Geophysical Research 112, C05043. doi:10.1029/2006JC003952.

Doglioli, A.M., Veneziani, M., Blanke, B., Speich, S., Griffa, A., 2006. A Lagrangian analysis of the Indian-Atlantic interocean exchange in a regional model. Geophysical Research Letters 33, L14611. doi:10.1029/2006GL026498.

Donners, J., Drijfhout, S.S., Coward, A.C., 2004. Impact of cooling on the water mass exchange of Agulhas rings in a high resolution ocean model. Geophysical Research Letters 31, L16312. doi:10.1029/2004GL02644.

Ducet, N., Le Traon, P.Y., Reverdin, G., 2000. Global high-resolution mapping of ocean circulation from TOPEX/Poseidon and ERS-1 and -2 . Journal of Geophysical Research 105 (C8), 19477-19498. 
Duncombe Rae, C.M., 1991. Agulhas retroflection rings in the South Atlantic Ocean; an overview. South African Journal of Marine Science 11, 327-344.

Flierl, G.R., 1981. Particle motions in large-amplitude wave fields. Geophysical and Astrophysical Fluid Dynamics 18 (1-2), 39-74.

Garzoli, S.L., Gordon, A.L., 1996. Origins and variability of the Benguela Current. Journal of Geophysical Research 101 (C1), 897-906.

Garzoli, S.L., Goni, G.J., Mariano, A.J., Olson, D.B., 1997. Monitoring the upper southeastern Atlantic transports using altimeter data. Journal of Marine Research 55 (3), 453-481.

Garzoli, S.L., Richardson, P.L., Duncombe Rae, C.M., Fratantoni, D.M., Goni, G.J., Roubicek, A.J., 1999. Three Agulhas rings observed during the Benguela Current experiment. Journal of Geophysical Research 104 (C9), 20971-20985.

Gladyshev, S., Arhan, M., Sokov, A., Speich, S., 2008. A hydrographic section from South Africa to the southern limit of the Antarctic Circumpolar Current at the Greenwich meridian. Deep-Sea Research I 55 (10), 1284-1303.

Goni, G.J., Garzoli, S.L., Roubicek, A.J., Olson, D.B., Brown, O.B., 1997. Agulhas ring dynamics from TOPEX/POSEIDON satellite altimeter data. Journal of Marine Research 55 (5), 861-883.

Gordon, A.L., Bosley, K.T., Aikman III, F., 1995. Tropical Atlantic water within the Benguela upwelling system. Deep-Sea Research I 42, 1-12.

Gordon, A.L., Haxby, W.F., 1990. Agulhas eddies invade the South-Atlantic-evidence from Geosat altimeter and shipboard conductivity-temperature-depth survey. Journal of Geophysical Research 95 (C3), 3117-3125.

Herbette, S., Morel, Y., Arhan, M., 2003. Erosion of a surface vortex by a seamount. Journal of Physical Oceanography 33 (8), 1664-1679.

Herbette, S., Morel, Y., Arhan, M., 2004. Subduction of a surface vortex under an outcropping front. Journal of Physical Oceanography 34 (7), 1610-1627.

Herbette, S., Morel, Y., Arhan, M., 2005. Erosion of a surface vortex by a seamount on the beta plane. Journal of Physical Oceanography 35 (11), 2012-2030.

Kamenkovich, V.M., Leonov, Y.P., Nechaev, D.A., Byrne, D.A., Gordon, A.L., 1996. On the influence of bottom topography on the Agulhas eddy. Journal of Physical Oceanography 26 (6), 892-912.

Le Traon, P.Y., Nadal, F., Ducet, N., 1998. An improved mapping method of multisatellite altimeter data. Journal of Atmospheric and Oceanic Technology 15 (2), 522-534.

Lutjeharms, J.R.E., 1981. Spatial scales and the intensities of circulation in the ocean areas adjacent to South-Africa. Deep-Sea Research Part A 28 (11), 1289-1302.

Lutjeharms, J.R.E., Cooper, J., 1996. Interbasin leakage through Agulhas Current filaments. Deep-Sea research I 43, 213-238.

Lutjeharms, J.R.E., Valentine, H.R., 1988. Eddies at the sub-tropical convergence south of Africa. Journal of Physical Oceanography 18 (5), 761-774.
Lutjeharms, J.R.E., Van Ballegooyen, R.C., 1988. The retroflection of the Agulhas Current. Journal of Physical Oceanography 18, 1570-1583.

Lutjeharms, J.R.E., Shillington, F.A., Duncombe Rae, C.M., 1991. Observations of extreme upwelling filaments in the southeast Atlantic-ocean. Science 253 (5021), 774-776.

McCartney, M.S., Woodgate-Jones, M.E., 1991. A deep-reaching anticyclonic eddy in the subtropical gyre of the eastern South Atlantic. Deep-Sea Research 38 (Suppl. 1), S411-S443.

McDonagh, E.L., Heywood, K.J., Meredith, M.P., 1999. On the structure, paths, and fluxes associated with Agulhas rings. Journal of Geophysical Research 104 (C9), 21007-21020.

Morrow, R., Birol, F., Griffin, D., Sudre, J., 2004. Divergent pathways of cyclonic and anti-cyclonic ocean eddies. Geophysical Research Letters 31, L24311. doi:10.1029/2004GL020974.

Orsi, A.H., Whitworth, T., Nowlin, W.D., 1995. On the meridional extent and fronts of the Antarctic Circumpolar Current. Deep-Sea Research I 42 (5), 641-673.

Penven, P., Lutjeharms, J.R.E., Marchesiello, P., Roy, C., Weeks, S.J., 2001. Generation of cyclonic eddies by the Agulhas Current in the lee of the Agulhas Bank. Geophysical Research Letters 28 (6), 1055-1058.

Richardson, P.L., 2007. Agulhas leakage into the Atlantic estimated with subsurface floats and surface drifters. Deep-Sea Research I 54, 1361-1389.

Rio, M.-H., Schaeffer, P., Lemoine, J.-M., Hernandez, F., 2005. Estimation of the ocean mean dynamic topography through the combination of altimetric data, in-situ measurements and GRACE geoid: from global to regional studies. In: Proceedings of the GOCINA International Workshop, Luxembourg.

Rio, M.-H., Hernandez, F., 2004. A mean dynamic topography computed over the world ocean from altimetry, in situ measurements, and a geoid model. Journal of Geophysical Research 109 (C12).

Rubio, A., Blanke, B., Speich, S., Grima, N., Roy, C., 2009. Mesoscale eddy activity in the southern Benguela upwelling system from satellite altimetry and model data. Progress in Oceanography). doi:10.1016/j.pocean.2009.07.029.

Schmid, C., Boebel, O., Zenk, W., Lutjeharms, J.R.E., Garzoli, S.L., Richardson, P.L., Barron, C., 2003. Early evolution of an Agulhas Ring. Deep-Sea Research II 50 (1), 141-166.

Schouten, M.W., de Ruijter, W.P.M., van Leeuwen, P.J., Lutjeharms, J.R.E., 2000. Translation, decay and splitting of Agulhas rings in the southeastern Atlantic Ocean. Journal of Geophysical Research 105 (C9), 21913-21925.

Shillington, F.A., Peterson, W.T., Hutchings, L., Probyn, T.A., Waldron, H.N., Agenbag, J.J., 1990. A cool upwelling filament off Namibia, southwest Africa-preliminary measurements of physical and biological features. DeepSea Research Part A 37 (11), 1753-1772. 